
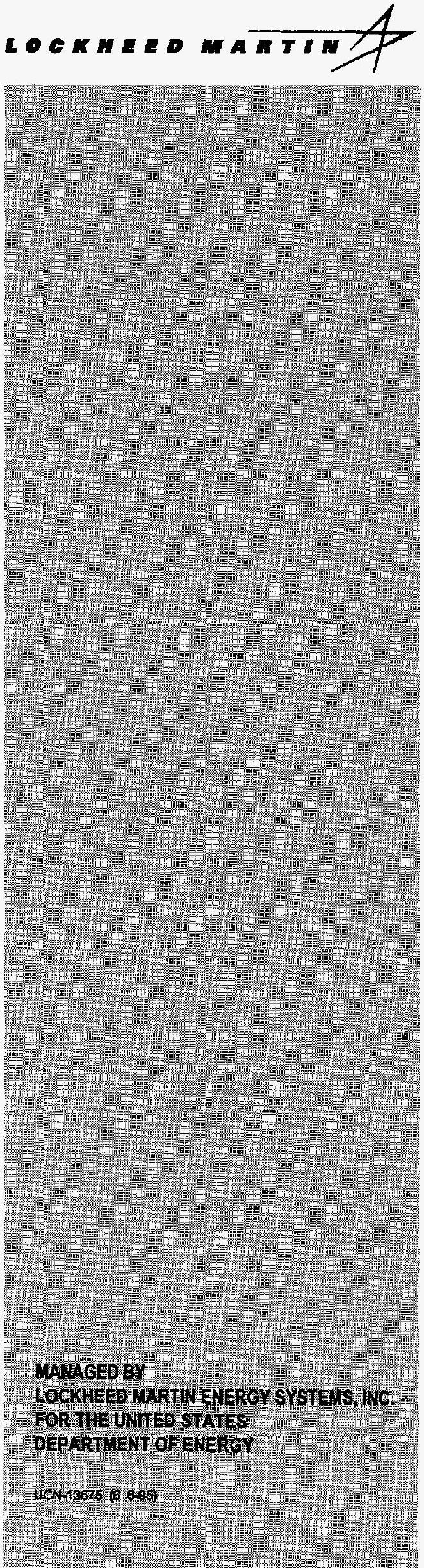

KUTSO-7
Oak Ridge Associated Universities, Oak Ridge, TN 37831 (Present address: Industrial Technology Research Institute, Taiwan, Republic of China) and

William D. Bostick Lockheed Martin Energy Systems, Inc., Oak Ridge, TN 37831-7274

April 1996 


\section{DISCLAIMER}

This report was prepared as an account of work sponsored by an agency of the United States Government. Neither the United States Government nor any agency or agent thereof, nor any of their employees, makes any warranty, express or implied, or assumes any legal liability or responsibility for the accuracy, completeness, or usefulness of any information, apparatus, product, or process disclosed, or represents that its use would not infringe privately owned rights. Reference herein to any specific commercial product, process, or service by trade name, trademark, manufacturer, or otherwise, does not necessarily constitute or imply its endorsement, recommendation, or favoring by the United States Government or any agency or agent thereof. The views and opinions of authors expressed herein do not necessarily state or reflect those of the United States Government or any agency thereof. 


\title{
TREATMENT OPTIONS FOR LOW-LEVEL RADIOLOGICALLY CONTAMINATED ORNL FILTERCAKE
}

\author{
Hom-Ti Lee \\ Oak Ridge Associated Universities, Oak Ridge, TN 37831 \\ (Present address: Industrial Technology Research Institute, Taiwan, Republic of China) \\ and \\ William D. Bostick \\ Lockheed Martin Energy Systems, Inc., Oak Ridge, TN 37831-7274 \\ Additional Contributions:
}

R. Adamski, D.E. Beck, G.R Cunningham, D.P. Hoffmann, C.J. Miller, L.E. Powell, W.A. Slover,

R.D. Spence, R.J. Stevenson, and T.L. White

Lockheed Martin Energy Systems, Inc., Oak Ridge, TN 37831

G.M.K. Abotsi

Clark Atlanta University,Atlanta, GA 30314-6890

T. Miller

Scientific Ecology Group, Inc., Oak Ridge, TN 37831-2530

J.A. Beck and R.D. Petersen

EET Corporation, Knoxville, TN 37932-3722

C. Jensen and P.M. Werner

Diversified Tecnologies Services, Knoxville, TN 37931-3111

April 1996

\author{
Prepared by \\ the Oak Ridge K-25 Site \\ Oak Ridge, Tennessee 37831-7274 \\ managed by \\ LOCKHEED MARTIN ENERGY SYSTEMS, INC. \\ for the \\ U.S. DEPARTMENT OF ENERGY \\ under contract DE-AC05-84OR21400
}

*under subcontract No. 19KAGB85V with Lockheed Martin Energy Systems, Inc.

This doxument has beea approyed for relense

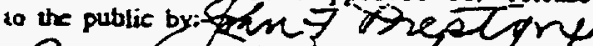

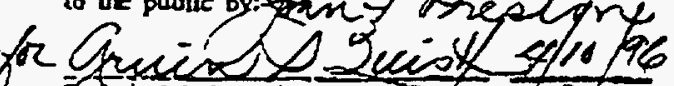




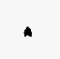

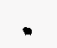

8

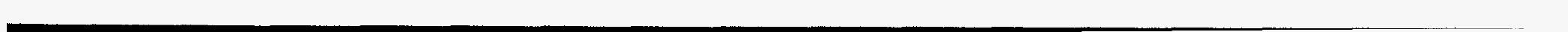


CONTENTS

Page

LIST OF TABLES $\ldots \ldots \ldots \ldots \ldots \ldots \ldots \ldots \ldots \ldots \ldots \ldots \ldots \ldots \ldots \ldots \ldots \ldots \ldots \ldots$

LIST OF FIGURES $\ldots \ldots \ldots \ldots \ldots \ldots \ldots \ldots \ldots \ldots \ldots \ldots \ldots \ldots \ldots \ldots \ldots \ldots \ldots$

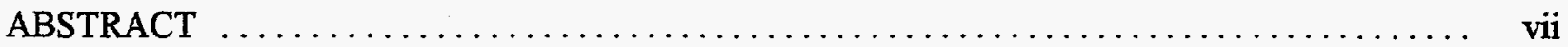

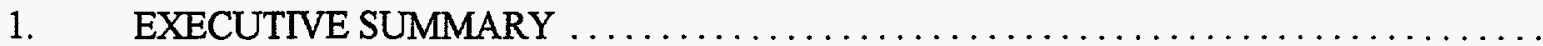

2. AUTHENTIC WATER SOFTENING SLUDGE $\ldots \ldots \ldots \ldots \ldots \ldots \ldots \ldots \ldots \ldots$

3. SURROGATE PREPARATION $\ldots \ldots \ldots \ldots \ldots \ldots \ldots \ldots \ldots \ldots \ldots \ldots \ldots \ldots \ldots \ldots \ldots \ldots \ldots$

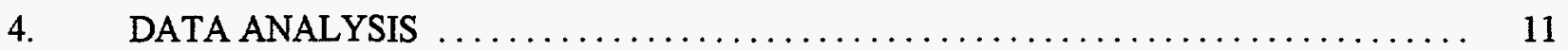

5. POLYMER ENCAPSULATION OF DRIED SURROGATE SOLIDS $\ldots \ldots \ldots \ldots \ldots \ldots$

6. HIGH-TEMPERATURE THERMAL PROCESSING $\ldots \ldots \ldots \ldots \ldots \ldots \ldots \ldots \ldots \ldots$

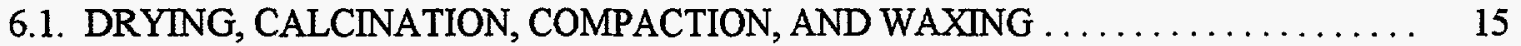

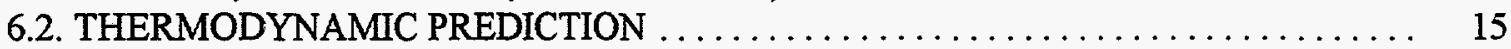

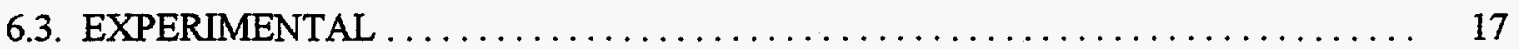

6.4. TIDE STABILIZATION PROCESS: SOLIDIFICATION/STABILIZATION OF

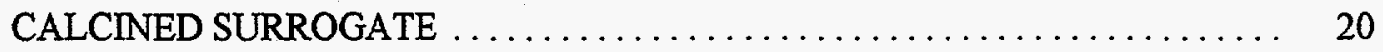

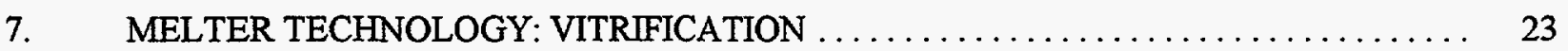

7.1. IN-CONTAINER MICROWAVE MELTING TEST $\ldots \ldots \ldots \ldots \ldots \ldots \ldots \ldots \ldots$

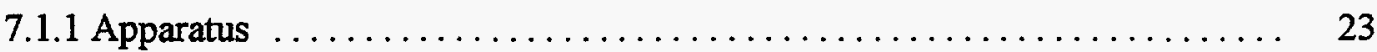

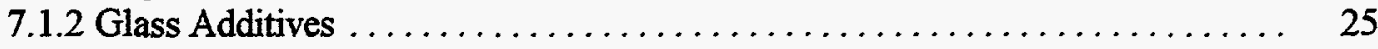

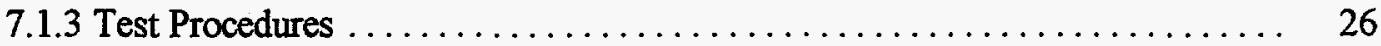

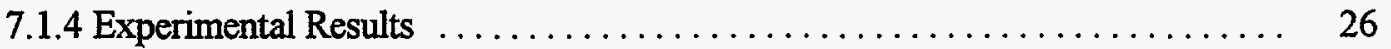

7.2. CONTINUOUS MICROWAVE MELTING $\ldots \ldots \ldots \ldots \ldots \ldots \ldots \ldots \ldots \ldots \ldots \ldots \ldots$

7.3. MICROWAVE MELT MINERALIZATION $\ldots \ldots \ldots \ldots \ldots \ldots \ldots \ldots \ldots \ldots \ldots$

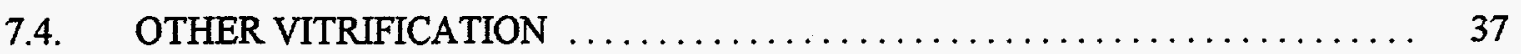

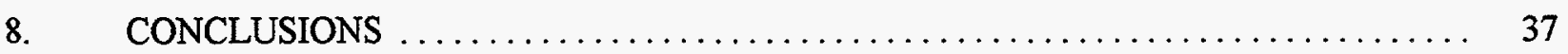

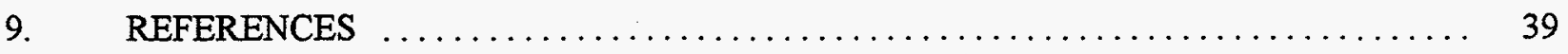

APPENDIX A

OPTIONS FOR IMMOBILIZATION OF ORNL PROCESS WASTE TREATMENT

FACILITY WATER SOFTENING SLUDGE, D. E. BECK ET AL., DECEMBER 1994. 


\section{LIST OF TABLES}

Table

Page

1. Comparison of surrogate (WSS-6) and authentic filtercake composite $(6175-71) \ldots \ldots .7$

2. Dry and calcine solids content for ORNL filtercake $\ldots \ldots \ldots \ldots \ldots \ldots \ldots \ldots \ldots \ldots$

3. Surrogate formulations (theoretical oxide equivalents, wt $\%$ ) $\ldots \ldots \ldots \ldots \ldots \ldots \ldots \ldots$

4. Thermodynamic predictions mass reduction ratio and $\mathrm{Cs}$ volatilization ${ }^{*} \ldots \ldots \ldots \ldots \ldots$

5. Summary of drying/calcination/compaction/waxing results $\ldots \ldots \ldots \ldots \ldots \ldots \ldots \ldots \ldots$

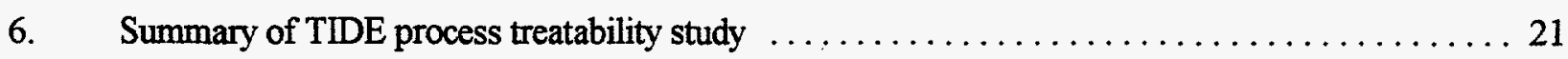

\section{LIST OF FIGURES}

Figure Page

1. Waste forms for ORNL filtercake (size of drum icon is proportional to the volume of the waste

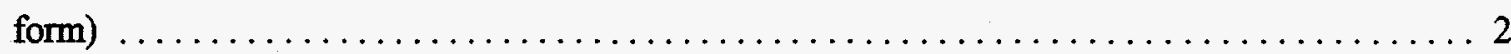

2. Typical storage array for as-generated raw sludge $\ldots \ldots \ldots \ldots \ldots \ldots \ldots \ldots \ldots \ldots \ldots \ldots \ldots$

3. Representative vinyl ester styrene waste forms $\ldots \ldots \ldots \ldots \ldots \ldots \ldots \ldots \ldots \ldots \ldots$

4. Surrogate waste wafers [pressed at $4500 \mathrm{lb} / \mathrm{in}^{2}$ (psi)]. Top row: pressed waste form; bottom row: fragments of pressed waste form placed in water . . . . . . . . . . . . . . . . 19

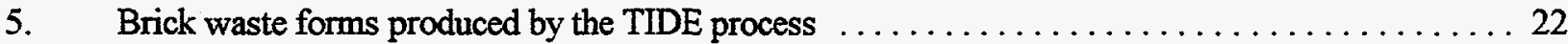

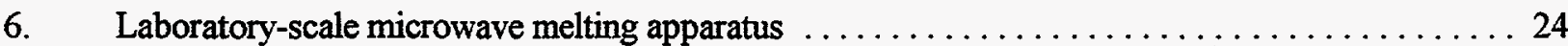

7. Representative microwave melt products (see text for material descriptions) $\ldots \ldots \ldots \ldots . \ldots 27$

8. Continuous-feed microwave melting apparatus (courtesy of T.L. White) $\ldots \ldots \ldots \ldots \ldots \ldots$

9. Waste forms from continuous-feed microwave melting apparatus $\ldots \ldots \ldots \ldots \ldots \ldots \ldots$

10. Polarized light image of a thin section from a wasteform produced by microwave melt

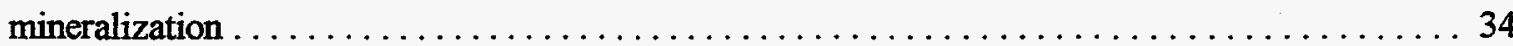




\begin{abstract}
Water softening sludge generated by the Process Waste Treatment Plant of Oak Ridge National Laboratory (ORNL) must be treated, stabilized, and placed in safe storage/disposal. More than 4000 drums of the low-level contaminated water softening sludge are now stored at ORNL and the Oak Ridge $\mathrm{K}-25$ Site, and an additional 600 drums per year are generated. The sludge is primarily calcium carbonate, with trace levels of $\mathrm{Mg}, \mathrm{Si}, \mathrm{Al}$, and $\mathrm{Fe}$; the material is nonhazardous by Resources Conservation and Recovery Act (RCRA) criteria, but it is contaminated by low levels of ${ }^{90} \mathrm{Sr}$ and ${ }^{137} \mathrm{Cs}$. The goal of the treatment is to minimize the volume of waste being stored on-site, while making a waste form (i.e., treated waste) that may qualify for eventual off-site disposal. The objective of this study is to identify appropriate technologies for the treatment of the sludge in terms of volume reduction, radionuclide stabilization, and elimination of free liquid. In this study, one emerging technology (i.e., microwave sintering) and one conventional technology (i.e., calcinination) were evaluated through laboratory-scale treatability studies.

The results of microwave melting experiments showed that it is a promising process to treat the sludge. The resultant volume reductions were significant (typically three- to fivefold) and the waste form was durable with appropriate glass additives. Both Lithium hydroxide and fly ash appeared to be viable glass additives to form consolidated and dense $(-2.7 \mathrm{~g} / \mathrm{cc})$ products. A commercial vendor, using surrogate, has demonstrated a melt mineralization process that uses minimal additives to yield a dense monolithic waste form representing a volume reduction factor (VR) of $\sim 7.7$.

Calcination of the sludge at 850 to $900^{\circ} \mathrm{C}$ yielded a VR of 2.5 and a mass reduction factor (MR) of 1.6. Similar results were found in surrogate tests. Followed by the compaction at $4500 \mathrm{psi}$, the VR was increased to -4.2 , but the compressed form is not dimensionally stable. Addition of paraffin helped consolidate fines and yielded a more stable form that resulted in an overall VR and MR of 3.5 and 3.1, respectively. However, the final waste form would not have the durability of glass or slag produced from vitrification processes.

In order to meet customer specifications of smallest possible wasteform volume, radionuclide stabilization, and minimum free liquid, microwave melting (or another form of vitrification) is likely to be the best among emerging technologies. For immediate implementation, the calcination/compaction/waxing process is a viable option.
\end{abstract}




\section{EXECUTIVE SUMMARY}

Most U.S. Department of Energy (DOE) industrial sites operate process wastewater treatment plants that produce large volumes of hazardous or mixed (hazardous and radiological) waste sludges. In an overview of DOE mixed waste inventories, the subcategory of "sludges, filtercakes, and residuals," generated primarily from wastewater treatment, represented the largest volume of waste that must be treated for compliance with the U. S. Environmental Protection Agency (EPA) regulations (Ross et al., 1992).

Oak Ridge National Laboratory (ORNL) Waste Management has a current inventory of $\sim 4000$ drums of low-level contaminated water softening sludge (filtercake), with a generation rate of -600 drums per year. This wastewater treatment residue is primarily calcium carbonate, with trace levels of $\mathrm{Mg}, \mathrm{Si}, \mathrm{Al}$, and $\mathrm{Fe}$; the material is nonhazardous by Resource Conservation and Recovery Act (RCRA) criteria, but it is contaminated by low levels of ${ }^{90} \mathrm{Sr}$ and ${ }^{137} \mathrm{Cs}$. The primary goal of treatment is to minimize the volume of waste being stored on-site, while making a product that may eventually qualify for off-site disposal.

This study consists of a review of treatment options and treatability studies. The review of viable options for immobilizing the ORNL filtercake includes a literature survey and some vendor interviews that provide a perspective of the strengths and weaknesses of the various proposed treatment options (included as an appendix to the main text). The treatment options evaluated in the literature review include cement grout, bitumen solidification, vitrification/melter technology, and polymer encapsulation.

The second part of this project carried out laboratory-scale treatability studies by using surrogates prepared in-house. Analysis of the authentic waste material indicates that it is predominantly water ( $\sim 60 \mathrm{wt} \%$, for a composite sample of as-stored sludge); therefore, some form of thermal processing would be expected to reduce the mass (and bulk volume) of the waste. A potential disadvantage of high-temperature processing (calcination or melting) is the possible volatilization of radiocesium (radiostrontium is relatively nonvolatile).

Treatment demonstrations, performed with use of surrogates, included (a) drying or calcination, followed by compaction and/or consolidation of fine particulate by incorporating the solid residue in a polymeric (wax or vinyl ester styrene encapsulation) binder or pozzolonic matrix (Phoenix Ash Technology TIDE process); and (b) microwave melting. With the exception of grout-based solidification, the results showed desirable volume and mass reductions for the final waste form. This is shown pictorially in Fig.1, in which the size of the drum icon is proportional to the volume of the resultant waste 


\section{THERMAL PROCESSING OF RAW SLUDGE}

\section{RAW SLUDGE ( $60 \%$ Water)}

55-gallon drum

(1) $80 \%$ capacity $=\mathbf{4 4}$ gallons

Specific Gravity $=1.28$

Mass = $367 \mathrm{lbs}(167 \mathrm{~kg})$

Mass Reduction Ratio $=1.0$

Volume Reduction Ratio $=1.0$

\section{DRY SOLIDS}

Mass $=147 \mathrm{lbs}(67 \mathrm{~kg})$

Mass Reduction Ratio $=\mathbf{2 . 5}$

Volume $=\mathbf{3 5}$ gallons

Volume Reduction Ratio $=1.3$

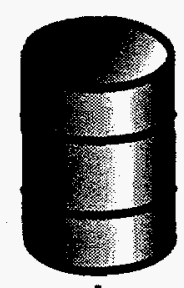

Dry

$\left(100-150^{\circ}\right)$

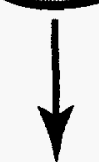

\section{CALCINE SOLIDS}

Mass $=39 \mathbf{~ k g}$

Mass Reduction Ratio $=\mathbf{4 . 3}$

Volume $=13.6$ gallons

Volume Reduction Ratio $=\mathbf{3 . 2}$

Calcine

$\left(800-1000^{\circ}\right)$

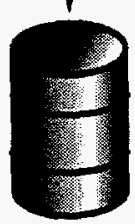

I

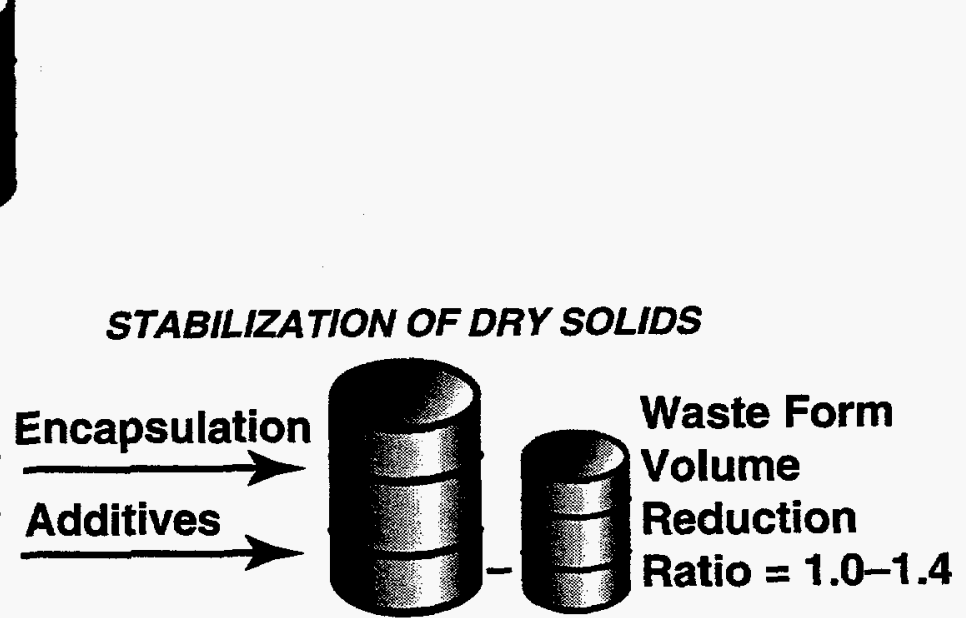

Ratio $=1.0-1.4$

MELTISTABILIZATION OF CALCINE SOLIDS
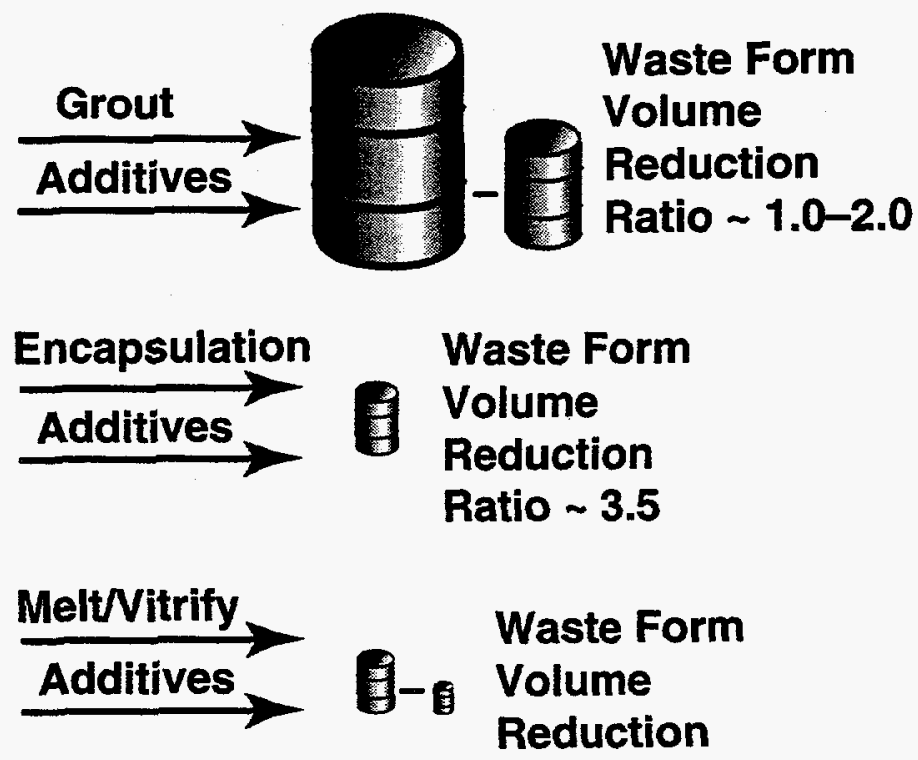

Ratio 4.0-7.6

Fig. 1. Waste forms for ORNL filtercake (size of drum icon is proportional to the volume of the waste form). 
form. The volume reduction ratio (VR) and the mass reduction ratio (MR) are defined as ratios of the original volume and mass of the raw waste before treatment to the volume and mass of the final waste form, respectively.

Merely drying the waste offers appreciable volume reduction and significant mass reduction (see Fig. 1), and should reduce the potential for container corrosion (Lomenick, 1992). Thus, drying is likely a desirable on-site pretreatment option, because costs of off-site transportation, treatment, and disposal will be proportionate to the mass or volume of the wastestream. However, the dry solids are easily dispersible and should be consolidated or carefully containerized to reduce this risk. If the drying operation is performed on-site, the condensate water could be returned to the treatment process (i.e., combined with the sludge filtrate stream).

A vendor (Diversified Technologies Services) demonstrated encapsulation of surrogate dry solids in vinyl ester styrene (VES) polymer. This technology, accepted by the U.S. Nuclear Regulatory Commission (NRC) for solidification of many types of radiological waste, yielded an excellent waste form, but (as demonstrated with dry solids, not calcines) did not yield a large VR. However, in terms of minimizing potential cesium volatilization, the VES process is more favorable than high-temperature processing.

Calcination of solids in a rotary kiln is a mature process. Calcination of the filtercake at 850 to $900^{\circ} \mathrm{C}$ yielded a VR of 2.5 and an MR of 1.6. Similar results were found from surrogate tests. Followed by the compaction at $4500 \mathrm{lbs} / \mathrm{in}^{2}{ }^{2}$ (psi), the VR was increased to 4.2 , but the compressed form is not dimensionally stable. Addition of paraffin helped consolidate fines to yield a more stable waste form, and resulted in overall VRs and MRs of 3.5 and 3.1, respectively. The calcination/compaction/waxing process is likely to be a viable near-term option for the filtercake treatment because of its immediate availability and competitive volume and mass reductions; however, the final waste form would not have the durability of glass or slag produced from vitrification processes. It is also necessary to design equipment capable of effectively mixing the calcines and the binding agents.

Solidification/Stabilization of waste in a cement grout host normally produces an increase in waste volume. The Technical Innovation Development Engineering (TIDE) proprietary solidification process uses a fast-setting pozzolonic reaction with a special grade of fly ash to incorporate waste into a pressed waste form that minimizes volume increase. However, this treatment does not provide competitive volume reduction (less than twofold) to stabilize the ORNL filtercake, as compared to microwave melting or the calcination/compaction/waxing process.

The results of laboratory-scale microwave melting experiments showed that it is a promising process to treat the ORNL water softening sludge. The resultant volume reductions were significant (by 
factors of $\sim$ fourfold) and the waste forms appeared durable when prepared with use of appropriate glass forming additives (e.g., silicate, sodium borax, etc.). Both lithium hydroxide and electric utility fly ash appeared to be viable glass additives to yield consolidated and dense $(\sim 2.7 \mathrm{~g} / \mathrm{cc})$ products.

Dr. T. L. White of Fusion Energy Division, ORNL, demonstrated a continuous-feed microwave melter that could be a viable technology to treat the filtercake in a full-scale operation mode. A commercial vendor (EET, Inc.) demonstrated a minimal additive (i.e., high waste loading) melting technology that yielded silicon-deficient monoliths having the highest VR ( 7.6).

In order to meet customer specifications of smallest possible waste form volume, radionuclide stabilization, and minimum free liquid, microwave melting and polymer encapsulation (VES process) are likely to be the best among emerging technologies. For immediate implementation, the calcination/compaction/waxing hybrid process is a viable option. 


\section{AUTHENTIC WATER SOFTENING SLUDGE}

Water softening sludge is generated at the ORNL's Process Waste Treatment Plant, Building 3504. About 60055 -gal drums per year of de-watered sludge are being added to a current inventory of more than 4000 drums in low-level waste storage facilities at ORNL and the Oak Ridge K-25 Site (see Fig. 2 for a typical storage array).

Previous testing (Walker, 1993) on randomly selected containers has shown that the sludge is not classified as RCRA-hazardous. The EPA Toxicity Characteristic Leaching Procedure (TCLP) indicated that the regulated metals $\mathrm{Ag}, \mathrm{As}, \mathrm{Cd}, \mathrm{Cr}, \mathrm{Pb}$, and Se were not detected in the leachate, and that $\mathrm{Ba}$ and $\mathrm{Hg}$ were found only at levels below permissible limits. No hazardous organic compounds were detected and sludge $\mathrm{pH}$ values were between 8.7 and 9.7 .

Radiological survey (gamma-spectroscopy) of ten archived samples indicates that the principal radioisotopes present in the stored sludge are ${ }^{137} \mathrm{Cs}(142$ to $7383 \mathrm{pCi} / \mathrm{g})$ and ${ }^{90} \mathrm{Sr}(13,000$ to 99,000 $\mathrm{pCi} / \mathrm{g}$ ). These relative values for radioisotopes in the sludge material are consistent with the fact that cesium salts are predominantly soluble in wastewater (and thus cesium is only incidentally present in partially dewatered sludge), whereas strontium behaves chemically similar to calcium, the predominant component in the sludge solids (vide infra). However, the presence of small amounts of radiocesium in the waste does present a potential challenge for high-temperature waste processing (calcination or melting), due to its relative volatility (Lee et al., 1994; Gibson et al., 1994; Burger, 1995).

A sample of authentic sludge composite from 302-4 Vault (sample log 6175-71) was obtained for our characterization. The sample is a buff-colored material with clay-like consistency, having a moisture content (determined by weight loss upon drying at 105 to $115^{\circ} \mathrm{C}$ ) of about $60 \%$ by weight. The wet sludge had a bulk density of about $1.28 \mathrm{~g} / \mathrm{cm}^{3}$, and the de-lumped dried solids had a tamp density of about $0.87 \mathrm{~g} / \mathrm{cm}^{3}$.

A sub-sample of dried 6175-71 material was submitted to K-25 Material Sciences Department for X-Ray Diffraction (XRD) analysis, which revealed calcite, $\mathrm{CaCO}_{3}$, as the major crystalline phase, with trace quartz, $\mathrm{SiO}_{2}$. Standardless Semi-Quantitative Energy-Dispersive X-Ray Spectroscopy (SSQEDS) was also performed, to provide a convenient "fingerprint" to identify major elemental constituents in the authentic filtercake specimen, and to allow comparison of the compositions of the authentic material and formulated surrogates, as Table 1 illustrates. The SSQ-EDS data reduction algorithm allows estimation as metal oxide equivalent weight percent. 


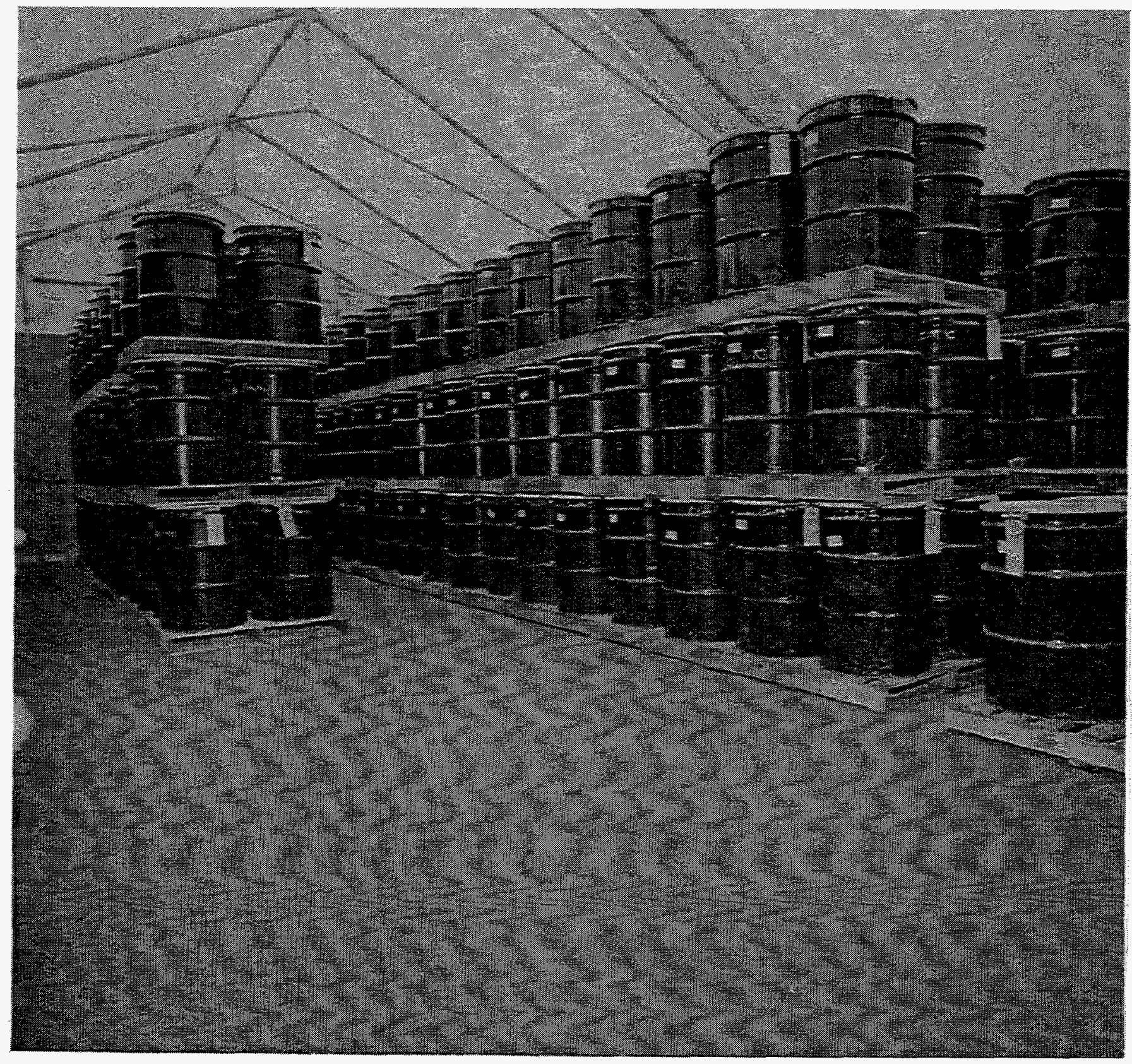

Fig. 2. Typical storage array for as-generated raw sludge. 
Table 1. Comparison of surrogate (WSS-6) and authentic filtercake composite (6175-71)

\begin{tabular}{|c|c|c|c|}
\hline \multirow{2}{*}{$\begin{array}{l}\text { Surrogate: } \\
\text { Chemicals Selected } \\
\text { As-Formulated }\end{array}$} & \multicolumn{2}{|c|}{$\begin{array}{c}\text { Surrogate: } \\
\text { Oxide Equivalent }\end{array}$} & \multirow{2}{*}{$\begin{array}{c}\text { Dried Filtercake Composite: } \\
\text { Oxide Equivalent }\end{array}$} \\
\hline & Theoretical Yield & SSQ-EDS Estimate & \\
\hline $\begin{array}{r}\mathrm{CaCO}_{3}: 163 \mathrm{~g} \\
(63.4 \mathrm{wt} \%)\end{array}$ & $\begin{array}{l}\mathrm{CaO}: 91.4 \mathrm{~g} \\
\quad(57.6 \mathrm{wt} \%)\end{array}$ & $\mathrm{CaO}: 55.6 \mathrm{wt} \%$ & $\mathrm{CaO}: 55.3$ wt \% \\
\hline $\begin{array}{r}\mathrm{MgCO}_{3}: 40.7 \mathrm{~g} \\
(15.8 \mathrm{wt} \%)\end{array}$ & $\begin{array}{l}\mathrm{MgO}: 19.5 \mathrm{~g} \\
\quad(12.3 \mathrm{wt} \%)\end{array}$ & $\mathrm{MgO}: 10.1 \mathrm{wt} \%$ & $\mathrm{MgO}: 12.4 \mathrm{wt} \%$ \\
\hline $\begin{aligned} & \mathrm{SiO}_{2}: 32.1 \mathrm{~g} \\
&(12.5 \mathrm{wt} \%)\end{aligned}$ & $\begin{aligned} & \mathrm{SiO}_{2}: 32.1 \mathrm{~g} \\
&(20.2 \mathrm{wt} \%)\end{aligned}$ & $\mathrm{SiO}_{2}: 19.9 \mathrm{wt} \%$ & $\mathrm{SiO}_{2}: 19.6 \mathrm{wt} \%$ \\
\hline $\begin{aligned} & \mathrm{Al}\left(\mathrm{OH}_{3}\right.: 8.7 \mathrm{~g} \\
&(3.4 \mathrm{wt} \%)\end{aligned}$ & $\begin{aligned} \mathrm{Al}_{2} \mathrm{O}_{3}: 5.7 \mathrm{~g} \\
(3.6 \mathrm{wt} \%)\end{aligned}$ & $\mathrm{Al}_{2} \mathrm{O}_{3}: 8.5 \mathrm{wt} \%$ & $\mathrm{Al}_{2} \mathrm{O}_{3}: 6.2 \mathrm{wt} \%$ \\
\hline $\begin{array}{r}\text { FeOOH: } 12.4 \mathrm{~g} \\
\quad(4.8 \text { wt \%) }\end{array}$ & $\begin{array}{l}\text { FeO: } 10.0 \mathrm{~g} \\
\quad(6.3 \mathrm{wt} \%)\end{array}$ & $\mathrm{FeO}: 5.9 \mathrm{wt} \%$ & FeO: $6.3 \mathrm{wt} \%$ \\
\hline $\begin{array}{l}\text { Total Mass: } 256.9 \mathrm{~g} \\
\text { (Sum wt } \%=99.9 \text { ) }\end{array}$ & $\begin{array}{l}\text { Total Mass: } 158.7 \mathrm{~g} \\
\text { (Sum wt } \%=100.0 \text { ) }\end{array}$ & $($ Sum wt $\%=100.0)$ & (Sum wt \% = 99.8) \\
\hline
\end{tabular}

A grab-sample of filtercake waste was evaluated by Dr. Tom Miller at the Scientific Ecology Group facility (Miller, 1995) as Table 2 shows. This sample had an average moisture content (determined by weight loss upon drying at $105^{\circ} \mathrm{C}$ ) of $\sim 68.2 \mathrm{wt} \%$ (i.e., was much wetter than the K-25 composite sample, containing $\sim 60 \%$ moisture). The dried solids were subsequently calcined at $\sim 850$ to $900^{\circ} \mathrm{C}$ for $4 \mathrm{~h}$, whereupon the average incremental weight loss was determined to be $\sim 41.8 \%$ (due primarily to additional dehydration and the decomposition of carbonate salts to yield the corresponding metal oxide).

[Note: for the surrogate formulation described in Table 1, the theoretical mass loss afforded by converting dry solids ( $256.9 \mathrm{~g}$, as-formulated) to the equivalent calcined oxides (158.7 $\mathrm{g}$, theoretical) is $\sim 38.2 \%$; the experimental weight loss (when surrogate dry solids were calcined at $860^{\circ} \mathrm{C}$ for $4 \mathrm{~h}$ ) was determined to be $\sim 37 \%$. This compares to the aforementioned $\sim 42 \%$ weight loss observed when authentic dried filtercake is calcined, suggesting that the chemicals selected for preparation of the surrogate dry solids are a realistic approximation to the chemical forms in the authentic sludge] 
Table 2. Dry and calcine solids content for ORNL filtercake content

\begin{tabular}{|c|c|c|c|}
\hline Property & K-25 Composite Sample & SEG Grab Sample & Calculation basis \\
\hline $\begin{array}{l}\text { Wet Sludge: } \\
\text { Density }\left(\mathrm{g} / \mathrm{cm}^{3}\right)\end{array}$ & 1.28 & 1.13 & 1.28 \\
\hline $\begin{array}{l}\text { Dry Solids Content }{ }^{\mathrm{a}} \\
\text { (g-dry solids/g-wet sludge) }\end{array}$ & 0.400 & 0.318 & 0.400 \\
\hline $\begin{array}{l}\text { Dry Solids: bulk density } \\
\left(\mathrm{g} / \mathrm{cm}^{3}\right)\end{array}$ & $0.87(\operatorname{tamp})$ & $\begin{array}{l}0.65 \text { (loose bulk) } \\
{[0.83, \text { pressed @ } 4500} \\
\text { psi] }\end{array}$ & \\
\hline $\begin{array}{l}\text { Calcine Solids: } \\
\text { g-calcine/g-dry solids }{ }^{b}\end{array}$ & & 0.577 & 0.577 \\
\hline $\begin{array}{l}\text { Calcine Solids: bulk } \\
\text { density }\left(\mathrm{g} / \mathrm{cm}^{3}\right)\end{array}$ & & 0.755 (loose bulk) & \\
\hline
\end{tabular}

${ }^{2}$ Fractional residual mass after wet sludge is dried at 100 to $110^{\circ} \mathrm{C}$.

${ }^{b}$ Fractional residual mass when dried solids are calcined at 850 to $900^{\circ} \mathrm{C}$. 


\section{SURROGATE PREPARATION}

The surrogates were prepared to mimic behaviors of the authentic sludge during treatment processes. Several batches of surrogate were prepared for treatability studies; each batch was compared to the authentic material with use of SSQ-EDS (as Table 1 illustrates). Several different reagent chemicals were used for surrogate preparation (e.g., in different formulations the magnesium component may have been provided in the form of the carbonate or hydroxide salt, as dolomitic limestone, or as the oxide); Table 3 describes the surrogates in terms of theoretical oxide equivalents (cf. Table 1).

Reagent-grade chemicals can be used to duplicate essential chemical composition, especially in high-temperature melter technology demonstrations that induce chemical and phase transformations, making the original chemical form of the surrogate chemical reagents less critical. However mimicking the authentic wet sludge consistency (to fairly assess issues of material handling, volume reduction upon low-temperature processing, etc.) requires that selected components (especially calcium carbonate) be generated in a manner analogous to the manner that they are produced in the authentic sludge (i.e., by precipitation from solution). For most of the surrogate preparations tested, the calcium carbonate component was prepared in-house by combining concentrated equimolar solutions of sodium sulfate and calcium chloride, then rinsing the precipitate with deionized water (see Tai and Chen, 1995). Typical "homemade" calcium carbonate products had surface areas of $\sim 5-20 \mathrm{~m}^{2} / \mathrm{g}$ (estimated by BrunauerEmmett-Teller (BET) theory), and could be used to prepare stiff paste-like filtercake surrogates containing about $40 \%$ solids. In contrast, a commercial $\mathrm{CaCO}_{3}$ reagent material (Malinckrodt) was essentially non-porous (surface area $\ll \mathrm{lm}^{2} / \mathrm{g}$ ), and surrogates prepared with this material had a very limited ability to absorb water, yielding a relatively thin slurry suspension at $\sim 40 \mathrm{wt} \%$ solids content.

The iron-containing component selected for use in surrogate preparation was either goethite $(\alpha-$ $\mathrm{FeOOH}$, or $\mathrm{Fe}_{2} \mathrm{O}_{3}{ }^{*} \mathrm{H}_{2} \mathrm{O}$, from NOAH Technologies) or hematite $\left(\mathrm{Fe}_{2} \mathrm{O}_{3}\right.$, from Alfa Products), which represent crystalline analogs to the amorphous hydrated ferric oxyhydroxide found in typical wastewater sludges (Baltpurvins et al., 1996). Note, however, that amorphous hydrated ferric oxyhydroxide is much better than the crystalline materials at binding water. For most surrogate preparations, the silica reagent source was diatomaceous earth (analogous to the material used as the filter aid to isolate the authentic sludge). 
Table 3. Surrogate formulations (theoretical oxide equivalents, wt \%)

\begin{tabular}{llllll}
\hline $\begin{array}{l}\text { Surrogate } \\
\text { Designation }\end{array}$ & $\mathrm{MgO}$ & $\mathrm{Al}_{2} \mathrm{O}_{3}$ & $\mathrm{SiO}_{2}$ & $\mathrm{CaO}$ & $\mathrm{FeO}$ \\
\hline WSS\#1 & 16.5 & 00.0 & 14.9 & 66.9 & 01.6 \\
WSS\#2,3 & 15.5 & 02.9 & 18.8 & 60.6 & 02.7 \\
WSS\#4 & 12.6 & 02.5 & 18.2 & 64.2 & 02.5 \\
WSS\#5 & 11.8 & 03.6 & 20.1 & 56.5 & 07.9 \\
WSS\#6 & 13.3 & 03.6 & 20.2 & 57.6 & 06.3 \\
WSS\#7 & 12.2 & 03.7 & 19.9 & 57.1 & 07.1 \\
TIDE-1 & 12.4 & 03.7 & 20.3 & 57.1 & 06.5 \\
EET-DL & 21.3 & 03.5 & 18.4 & 50.0 & 05.6 \\
\hline \hline
\end{tabular}




\section{DATA ANALYSIS}

In order to get consistent comparisons, the mass reduction and volume reduction ratios used in this study were referenced to the properties of authentic, as-stored ORNL sludge (viz, composite sample 6175-71: wet sludge density $=1.28 \mathrm{~g} / \mathrm{cm}^{3}$, containing $\sim 60 \mathrm{wt} \%$ moisture and $\sim 40 \mathrm{wt} \% \mathrm{dry}$ solids). Furthermore, based upon the work by Miller (1995), it is assumed that, for example, $100 \mathrm{~g}$ of calcine product is the equivalent of $173.3 \mathrm{~g}$ of dried sludge solids (i.e, an incremental $42.3 \%$ weight loss upon calcination of dried sludge, or $0.577 \mathrm{~g}$-calcine/g-dry solids). Table 2 summarizes the parameters assumed for calculation of the equivalent volume of as-stored wet sludge.

By this convention, $100 \mathrm{~g}$ of calcined waste (metal oxides) is equivalent to $173.3 \mathrm{~g}$ of dried sludge solids, which in turn is equivalent to $433.2 \mathrm{~g}$ of "composite" wet sludge, having a volume of $338.5 \mathrm{~cm}^{3}$.

The mass reduction ratio, $M R$, is defined as:

$$
M R=\frac{M_{0}}{M_{f}}
$$

where $M_{0}$ represents the equivalent weight (referenced to genuine sludge) of the surrogate before treatment and was calculated by:

$$
M_{0}=\frac{(\text { mass of surrogate }) *(\text { solid } w t \% \text { of surrogate })}{(\text { solid } w t \% \text { of genuine } W S S, 40 \%)}
$$

and $M_{f}$ is the weight of the mixture of surrogate solids and binders or glass additives after treatment and was directly measured for each run.

VR is defined as:

$$
V R=\frac{V_{0}}{V_{f}}
$$


The waste volume before treatment, $V_{0}$, was calculated based on $M_{0}$ and the density of the genuine sludge (i.e., $1.28 \mathrm{~g} / \mathrm{cm}^{3}$ as listed in Table 2). The $V_{f}$ is calculated based on measured skeleton density and weight of the waste form after treatment. Some waste forms were notably porous due to the presence of gas bubbles. In some instances, we estimated a "geometric" volume reduction factor, based upon the measurement of the volumetric displacement of the waste form ("Archimedes" principle"). 


\section{POLYMER ENCAPSULATION OF DRIED SURROGATE SOLIDS}

Encapsulation of low-level waste in polymer materials includes use, since the mid-1980s, of epoxy resins, vinyl ester styrene (VES), or polyethylene to create solid waste forms. The advantages of using this technology include high solidification efficiency, assured solidity, and high waste loading capacity (see Appendix 1). In a previous study (Morgan and Bostick, 1992), VES forms containing ionexchange resins performed well in durability testing. According to a local vendor, Diversified Technologies Services, Inc, the VES waste form is in compliance with 10 CFR Part 61 , is approved by the NRC for stabilization of classes $A, B$, and $C$ radioactive wastes, and meets Hanford Waste Acceptance Criteria (WAC) for burial. The vendor proposed use of a system called SludgeHammer ${ }^{\mathrm{TM}}$, which is an integrated mobile treatment unit that separates, volume reduces, and stabilizes sludges, resins, and other wet solids from aqueous phases. The concept incorporates centrifugal separation and a sludge dryer, with continuous screw-feed mixing of the dried solids with uncured VES or other binding agent. In a tabletop demonstration using dried surrogate material and VES, performed without optimizing the process conditions, the company produced a solidified waste form containing a waste loading of $\sim 60 \%$ by bulk volume (or $36.3 \%$ by weight). For the modest waste loading used in the unoptimized demonstration (hand-mixing of solids into VES), the estimated VR is only $\sim 0.8$. The processing yielded a peak temperature of $94.2^{\circ} \mathrm{C}$ with a gelation time of $\sim 17 \mathrm{~min}$ (Werner, 1995). One advantage of this technology over microwave melting and rotary kiln calcination is that most ${ }^{137} \mathrm{Cs}$ should be retained within the waste form because the operating temperature is well below the volatility threshold for cesium. Figure 3 shows some VES encapsulated waste forms; the technology worked well for consolidation of various treatment residues such as fly ash, dried filter cake surrogate, and ion exchange resin. It is anticipated that additional VR would be achieved if calcines, rather than dried solids, were encapsulated; however, the sludgehammer concept was not designed to achieve temperatures sufficient to achieve calcination. If calcined solids were encapsulated in VES at about $36 \mathrm{wt} \%$, the estimated VR would improve to $\sim 1.4$. 


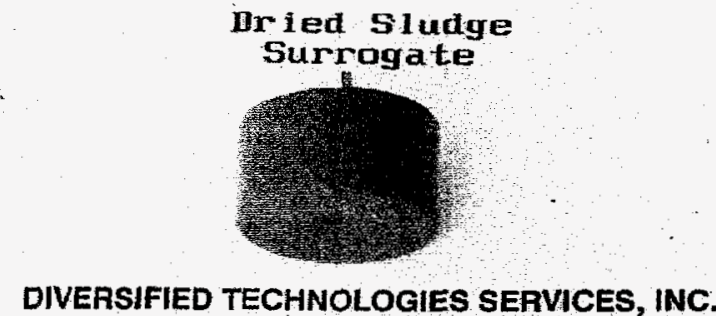

\section{Fly Ash}

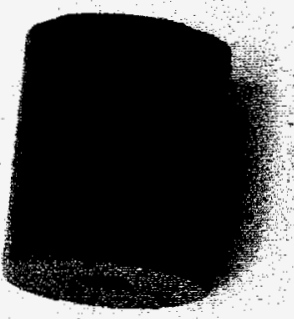

RESIN AND SLUDGE SOLIDIFICATION TECHNOLOGY DEMONSTRATION in compororito vith ERWM CHEMISTRY AND MATERIALS LABORATORY son the

CENTERFOR ENVIAONMENTAL TECHNOLOOY

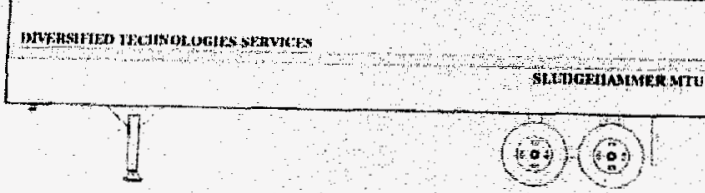

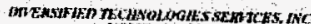

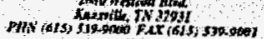

Ion Exchange Resin

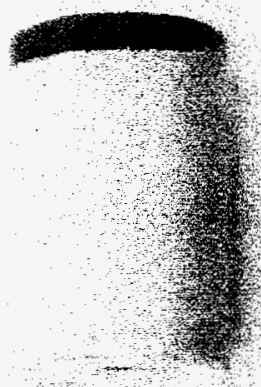

Fig. 3. Representative vinyl ester styrene waste forms. 


\section{HIGH-TEMPERATURE THERMAL PROCESSING}

High-temperature thermal processing of the filtercake sludge should further reduce its mass (due to decomposition of carbonate salts), but with a concurrent increase in the risk of loss of relatively volatile radiocesium to the process offgas.

\subsection{DRYING, CALCINATION, COMPACTION, AND WAXING}

Scientific Ecology Group, Inc. (SEG) has proposed use of a vacuum retort process to treat ORNL's filtercake waste. As originally proposed, the process would utilize a self-contained, high temperature, vacuum rotary kiln capable of drying and calcining mixtures in batch mode of operation. The kiln is indirectly heated from a furnace that uses No.2 fuel oil. The kiln is designed to rotate on a fixed retort $(10 \mathrm{rpm})$ to allow quick breakup of any solid material (Aulbaugh and Hawk, 1995). The normal system operation maintains vacuum $\left(12\right.$ to $22^{\prime \prime} \mathrm{Hg}$ ) at a temperature of at least $850^{\circ} \mathrm{C}$ (Miller, 1995).

High temperature calcination can yield significant mass reduction by driving off free water and carbon dioxide from the sludge. However, the treated waste may have significant porosity due to the release of carbon dioxide from the sludge. The resultant low density waste form might give an unfavorable volume reduction. Therefore, further treatments such as high pressure compaction and waxing may be necessary to achieve a durable waste form with acceptable volume reduction. A series of theoretical calculations and lab-scale tests were performed to find the figure of merit of the proposed process. The results are described in the following sections.

\subsection{THERMODYNAMIC PREDICTION}

A set of thermodynamic equilibrium calculations were performed, assuming a simplified filtercake surrogate composition, to estimate the ultimate extent of calcination, the corresponding mass reductions, and the cesium volatility. Although not shown here, most strontium is believed to be retained in the sludge during the treatment because previous studies (Lee et al., 1994; Gibson et al., 1994) have shown that strontium is quite refractory. The calculations were performed by the use of commercial computer software, HSC Chemistry for Windows, Ver. 2.0. The software contains a large chemical database and algorithms for calculations of reaction outcomes, heat and material balances, equilibrium compositions, phase stability diagrams, and electrochemical equilibria. The title "HSC" stands for 
enthalpy $(\mathrm{H})$, entropy $(\mathrm{S})$, and heat capacity (C). Based upon the information from SEG (Miller, 1995), bounding conditions were assumed to be temperature $\left(800\right.$ to $\left.1000^{\circ} \mathrm{C}\right)$ and pressure $(12$ to $22 \mathrm{in} . \mathrm{Hg}$, or 0.4 to 0.7 bar). The results (as shown in Table 4 for a simplified surrogate formulation) indicated that:

(1) The extent of calcination of $\mathrm{CaCO}_{3}$ ranged from 84.5 to $99.5 \%$ under the proposed operation conditions. The corresponding MRs ranged from 3.55 to 3.76. The percent cesium volatilization ranged from 84.53 to $98.07 \%$.

(2) Higher operating temperature results in more complete calcination and more cesium volatilization.

(3) Vacum operation can increase the extent of calcination and the percent cesium volatilization.

(4) For conventional calcination (atmospheric pressure), decomposition of $\mathrm{CaCO}_{3}$ and volatilization of cesium are essentially complete at temperatures greater than about $850^{\circ} \mathrm{C}$.

Table 4. Thermodynamic predictions mass reduction ratio and $\mathrm{Cs}$ volatilization*

\begin{tabular}{ccccc}
$\begin{array}{c}\text { Temperature } \\
\left({ }^{\circ} \mathrm{C}\right)\end{array}$ & $\begin{array}{c}\text { Pressure } \\
\text { (bar) }\end{array}$ & $\begin{array}{c}\text { \% } \mathrm{CaCO}_{3} \\
\text { Calcination }\end{array}$ & $\begin{array}{c}\text { Mass Reduction } \\
(\mathrm{MR})\end{array}$ & $\begin{array}{c}\text { \% Cs } \\
\text { Volatilization }\end{array}$ \\
\hline \multirow{2}{*}{800} & 0.4 & 92.4 & 3.66 & 93.23 \\
& 0.7 & 88.1 & 3.60 & 88.54 \\
& 1.0 & 84.5 & 3.55 & 84.53 \\
900 & 0.4 & 98.2 & 3.74 & 96.72 \\
& 0.7 & 97.0 & 3.72 & 94.37 \\
& 1.0 & 95.9 & 3.71 & 92.13 \\
1000 & 0.4 & 99.5 & 3.76 & 98.07 \\
& 0.7 & 99.2 & 3.76 & 96.67 \\
& 1.0 & 98.8 & 3.75 & 95.31 \\
\hline \hline *Waste composition (wt \%): $\mathrm{CaCO}_{3}(24 \%), \mathrm{MgCO}_{3}(9 \%), \mathrm{SiO}_{2}(4.1 \%), \mathrm{H}_{2} \mathrm{O}(62.9 \%), \mathrm{Cs}(100$ ppm as CsCl$)$.
\end{tabular}

The thermodynamic predictions provided the index of theoretically achievable mass reduction. However, due to the porosity formed during calcination, the predictions cannot provide the information for resultant volume reduction. 


\subsection{EXPERIMENTAL}

A series of tests were carried out to evaluate the performance of different treatment processes. The processes included drying, calcination, compaction, polymer encapsulation (waxing), and some combinations of these treatments. Table 5 summarizes the test results.

Table 5. Summary of drying/calcination/compaction/waxing results*

\begin{tabular}{|c|c|c|c|c|c|c|c|}
\hline Treatment & Materials & $\begin{array}{l}\text { Product } \\
\text { density } \\
(\mathrm{g} / \mathrm{cc})^{* *}\end{array}$ & $\begin{array}{l}\text { Final } \\
\text { mass } \\
(\mathrm{g}) \\
\end{array}$ & $\begin{array}{l}\text { Final } \\
\text { Volume } \\
\text { (cc) } \\
\end{array}$ & $\mathrm{MR}$ & VR & Remark \\
\hline \multirow{3}{*}{$\begin{array}{l}\text { Dried @ } \\
\sim 110^{\circ} \mathrm{C}\end{array}$} & $\begin{array}{l}\text { ORNL } \\
\text { WSS }\end{array}$ & 0.87 & 37.1 & 42.6 & 2.70 & 1.83 & $\mathrm{~K}-25$ composite \\
\hline & $\begin{array}{l}\text { ORNL } \\
\text { WSS }\end{array}$ & 0.83 & 37.1 & 44.7 & 2.70 & 1.75 & $\begin{array}{l}\text { SEG grab- } \\
\text { sample }\end{array}$ \\
\hline & WSS\#6 & 0.64 & 37.1 & 58.0 & 2.70 & 1.34 & \\
\hline $\begin{array}{l}\text { Dried \& } \\
\text { Pressed @ }\end{array}$ & WSS\#6 & & 37.1 & & 2.70 & & \\
\hline $\begin{array}{l}4500 \mathrm{psi} \\
6000 \mathrm{psi} \\
8000 \mathrm{psi} \\
\end{array}$ & & $\begin{array}{l}1.25 \\
1.28 \\
1.30 \\
\end{array}$ & & $\begin{array}{l}29.7 \\
29.0 \\
28.5 \\
\end{array}$ & & $\begin{array}{l}2.63 \\
2.69 \\
2.74 \\
\end{array}$ & \\
\hline \multirow[t]{2}{*}{ Calcination } & $\begin{array}{l}\text { ORNL } \\
\text { WSS }\end{array}$ & 0.753 & 23.3 & 30.9 & 4.29 & 2.53 & $\begin{array}{l}850 \text { to } 900^{\circ} \mathrm{C} \\
\text { for } 4 \mathrm{hrs}\end{array}$ \\
\hline & WSS\#6 & $0.48^{\dagger}$ & 23.3 & 48.5 & 4.29 & 1.61 & \\
\hline $\begin{array}{l}\text { Calcination } \\
\& \text { Press }\end{array}$ & WSS\#6 & 1.245 & 23.3 & 18.7 & 4.29 & 4.18 & 4500 psi \\
\hline $\begin{array}{l}\text { Calcination } \\
\& \text { Wax }\end{array}$ & WSS\#6 & 0.774 & 32.36 & 41.8 & 3.09 & 1.87 & $\begin{array}{l}\text { calcine/paraffin } \\
=72 / 28\end{array}$ \\
\hline $\begin{array}{l}\text { Calcination\& } \\
\text { Wax \& Press }\end{array}$ & WSS\#6 & 1.46 & 32.36 & 22.2 & 3.09 & 3.52 & $\begin{array}{l}\text { calcine/paraffin } \\
=72 / 28 \\
4500 \text { psi }\end{array}$ \\
\hline
\end{tabular}

*Basis for MR/VR calculations: $100 \mathrm{~g}$ wet filtercake $(1.28 \mathrm{~g} / \mathrm{cc})=37.1 \mathrm{~g}$ solids $($ dried $)=23.3 \mathrm{~g}$ calcines **Tap density

${ }^{\dagger}$ Skeletal density $=2.764 \mathrm{~g} / \mathrm{cc}$

Dried and calcined solids have a variable and relatively low bulk density $(<1 \mathrm{~g} / \mathrm{cc})$, with associated fine particulate fractions. The major crystalline phases of dried and calcined samples are $\mathrm{CaCO}_{3}$ (calcite) and $\mathrm{CaO}$ (lime), respectively. To achieve improved volume reduction, the dried and calcined product must be compressed (see Table 5). However, the compressed form is not dimensionally 
stable (i.e., it grows in dimensions when exposed to ambient air). This results in part from the hydration of calcium oxide and the uptake of atmospheric carbon dioxide. A series of tests of compression of freshly calcined calcium carbonate were conducted by Dr. G. Abotsi at Clark Atlanta University. The tests loaded $\sim 14.0 \mathrm{~g}$ of calcined product $\left(\mathrm{CaCO}_{3}\right.$ heated at $850^{\circ} \mathrm{C}$ for $4 \mathrm{~h}$, to form $\left.\mathrm{CaO}\right)$ in a 3.2-cm mold cylinder in a Buehler Specimen Mount Press. The samples, pressed at 4000,6000, and 8000 psi, grew in diameter from $3.2 \mathrm{~cm}$ to $4.2 \mathrm{~cm}$ in 3 days, to $4.5 \mathrm{~cm}$ in 3 days, and to $3.7 \mathrm{~cm}$ in 2 days, respectively. Addition of a hydrophobic binder/wetting agent helps consolidate fines and improves waste form performance in a humid environment. This is shown in Figure 4; the waste form in which the calcine solids are compressed with paraffin wax retains dimensional stability, even when submerged in water. As shown in Table 5, a surrogate study involving calcination, compaction, and waxing achieved a comparable volume reduction to vitrification process (i.e., 3.5 versus $\sim 4$ ). The wax-impregnated waste form would not have the durability of glass or slag (by NRC criteria), but may meet the ORNL on-site repository requirements. Similarly conditioned waste forms, using wax as a binding agent to render powdered waste non-dispersible, have been approved for disposal at the Barnwell, SC, repository (Autry, 1992).

A "pilot-scale" technology demonstration in which authentic filtercake material was processed by co-firing with coal in a low-level waste incinerator (rather than a vacuum calciner, as previously proposed) was performed at SEG. The resulting ash material was consolidated by compressing with wax. Based upon an as-received wet sludge density of $1.17 \mathrm{~g} / \mathrm{cm}^{3}\left(73 \mathrm{lb} / \mathrm{ft}^{3}\right)$, the overall VR was reported to be 3.08 (T. Miller, SEG, communication with G. Cunningham, March 1996). For the reference composite sludge at $1.28 \mathrm{~g} / \mathrm{cm}^{3}$, this would correspond to a VR $\sim 2.8$. This VR is less than that observed in laboratory studies using calcined surrogate, in part due to the co-immobilized coal ash. 
PRESSED SURROGATE

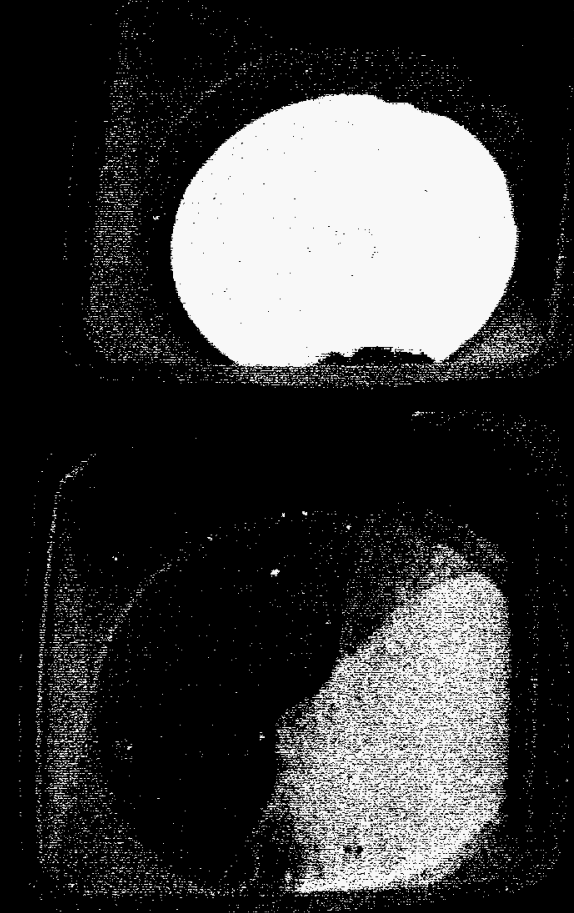

\section{CALCINE SURROGATE}
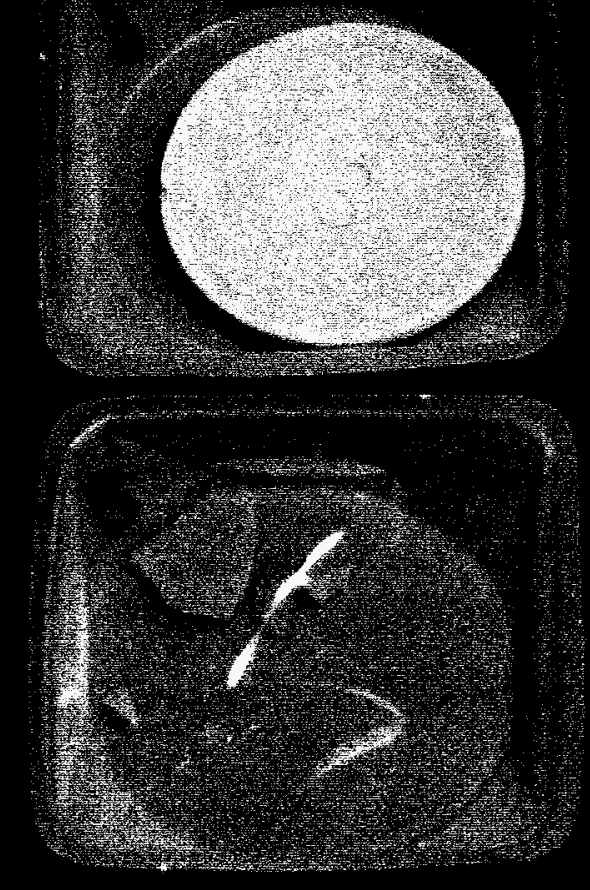

\section{CALCINE SURROGATE + WAX}
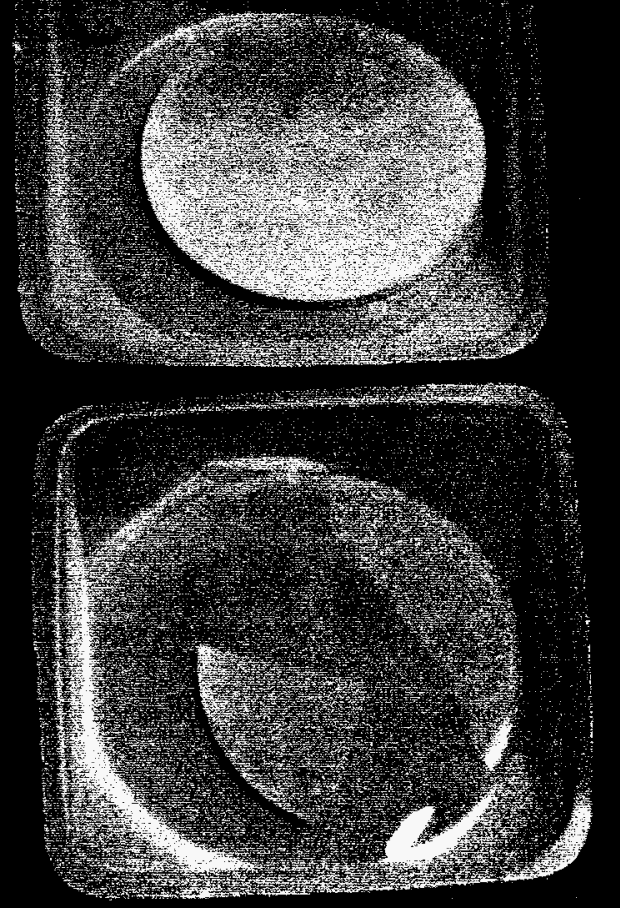

(72\% Calcine/28\% Wax)

Fig. 4. Surrogate waste [pressed at $4500 \mathrm{lb} / \mathrm{in}^{2}{ }^{2}$ (psi)]. Top row: pressed waste form; bottom row: fragments of pressed waste form placed in water. 


\subsection{TIDE STABILIZATION PROCESS: SOLIDIFICATION/STABILIZATION OF CALCINED SURROGATE}

The Technical Innovation Development Engineering (TIDE) Company has developed a patented process, the Phoenix Ash Technology, to create formed cementious products for use in construction or for waste stabilization/solidification. The process encapsulates waste using a reactive American Society for Testing and Materials (ASTM) Class C fly ash reagent (hydraulic binder) and a small amount of water, pressing the mixture (at $\sim 2000 \mathrm{psi}$ ) into formed bricks (Spence et al., 1994). The fly ash used is a fast-setting pozzolanic material, and the pressed bricks normally have good structural stability when initially removed from the form, and continue to gain strength with longer cure time.

Recently, Arnold and Diel (1995) reported preliminary testing of the TIDE process for stabilization of raw sludge from the Y-12 West End Treatment Facility (WETF). The WETF sludge, like the ORNL filtercake, contains calcium carbonate as the principal solid constituent. The investigators were unable to form a waste form with a high waste loading and with satisfactory physical integrity; they attributed this, in part, to the high water content (and water affinity) of the raw waste.

In order to control the water content of the waste/binder blend, and to enhance volume reduction, the filtercake surrogate (i.e., TIDE-1) was calcined $\left(-850^{\circ} \mathrm{C}\right.$ for $\left.4 \mathrm{~h}\right)$ prior to testing with the TIDE process. Two runs were carried out with different waste loadings (i.e., $60 \%$ and $21 \%$ by calcine weight). The additives used included TIDE fly ash, water, and/or blast furnace slag. The slag consists of metal oxides, mainly calcite and silicate. With $60 \%$ of waste loading, the yielded MR and VR were 1.97 and 1.82 , respectively; and with $21 \%$ of waste loading, they were 0.7 and 0.87 . The bricks cracked, although they did not crumble; the one having a lower waste loading has a better physical integrity, as Figure 5 shows. Table 6 summarizes experimental parameters. 
Table 6. Summary of TIDE process treatability study

\begin{tabular}{|c|c|c|}
\hline Run & WSS\#8-1 & WSS\#8-2 \\
\hline Surrogate WSS\#8 (g) & 247 & 95 \\
\hline Equivalent $\mathrm{M}_{0}(\mathrm{~g})$ & 665.8 & 256.1 \\
\hline Equivalent $V_{0}\left(\mathrm{~cm}^{3}\right)$ & 520.1 & 200.1 \\
\hline Calcined Surrogate (g) & 182 & 70 \\
\hline $\begin{array}{l}\text { Additives } \\
\text { Slag (g) } \\
\text { TIDE fly ash (g) } \\
\text { Water (g) }\end{array}$ & $\begin{array}{l}0 \\
120 \\
98\end{array}$ & $\begin{array}{l}70 \\
200 \\
60\end{array}$ \\
\hline Total (g) & 400 & 400 \\
\hline $\begin{array}{l}\text { Product (Brick) } \\
\text { Mass }(\mathrm{g}) \\
\text { Dimension }\left(\mathrm{L}^{*} \mathrm{~W}^{*} \mathrm{H}, \mathrm{cm}\right) \\
\text { Volume }\left(\mathrm{cm}^{3}\right)\end{array}$ & $\begin{array}{l}338.6 \\
12.8 * 6.5 * 3.5 \\
286\end{array}$ & $\begin{array}{l}363.9 \\
12.8 * 6.5 * 2.8 \\
230\end{array}$ \\
\hline Mass Reduction, MR & 1.97 & 0.7 \\
\hline Volume Reduction, VR & 1.82 & 0.87 \\
\hline
\end{tabular}




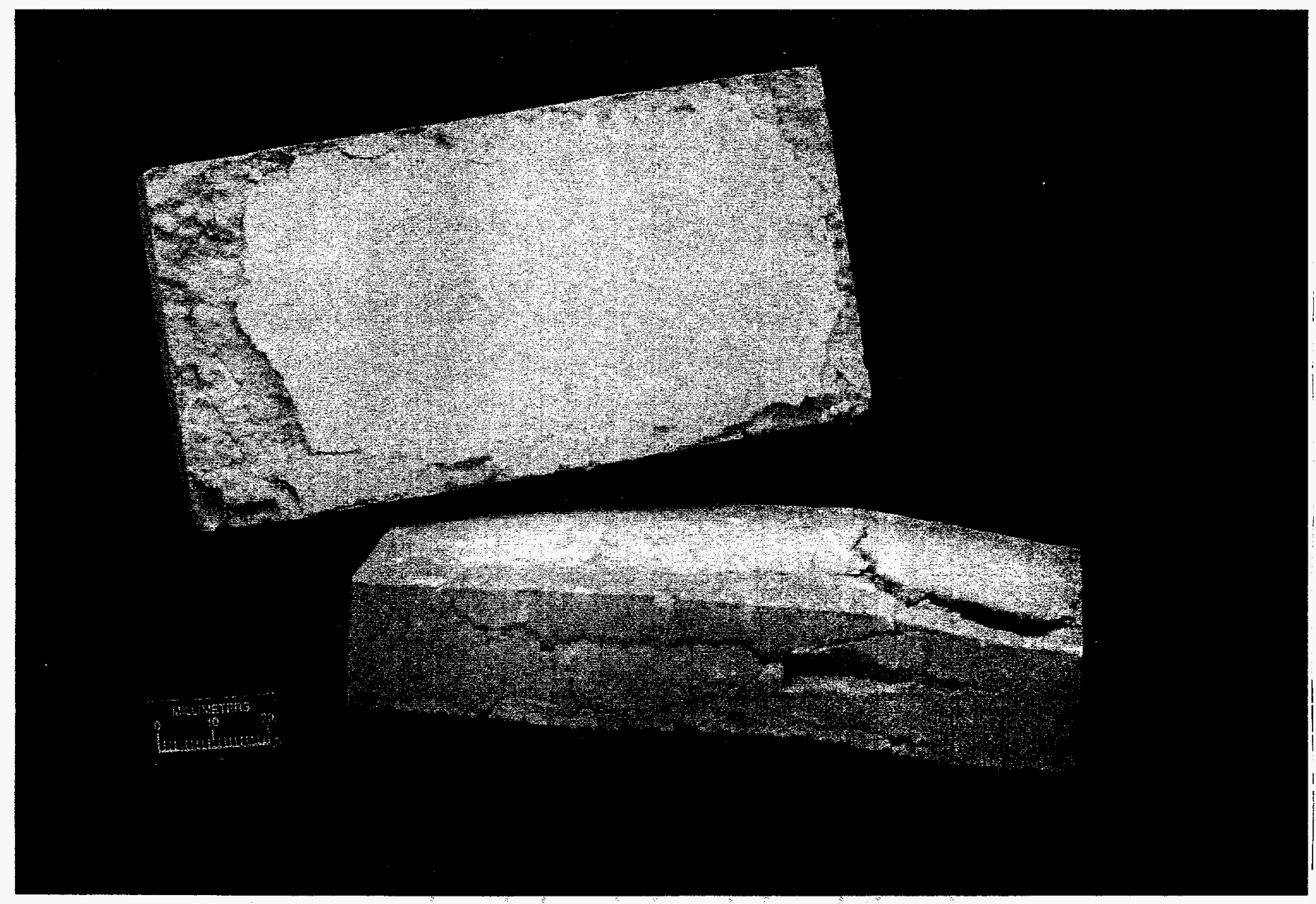

Fig. 5. Brick waste forms produced by the TIDE process. 


\section{MELTER TECHNOLOGY: VITRIFICATION}

Previous studies (Bescher et al,, 1991; Petersen and Sprenger, 1993; Sprenger and Eschen, 1993; Del Cul et al., 1994; White. 1995; White et al., 1995) have shown that the microwave heating process is capable of treating waste sludges, ashes, and liquid radioactive wastes. Microwaves are within the $300 \mathrm{MHZ}$ to $300 \mathrm{GHz}$ range of the electromagnetic spectrum. During the microwave heating process, the electromagnetic field may cause vibration of dipole molecules, oscillation of the magnetic components, and/or current through electrically conductive substances, depending upon the nature of the material. Consequently the temperature of the material absorbed microwave energy is elevated. Advantages of the technology include: (a) Direct heating by microwave eliminates the needs of heating elements and heat transfer surfaces, thus improving the maintainability; (b) The process can be batch, continuous, or in-drum; and (c) the waste form, with appropriate additives, can be durable glass and/or crystalline material which is suitable for final disposal/storage.

A series of microwave melting tests were performed to evaluate the effectiveness of the technology to produce durable waste forms with favorable volume and mass reductions. The resultant slag materials were subjected to X-Ray Diffraction (XRD) analysis to characterize their crystalline components.

\subsection{IN-CONTAINER MICROWAVE MELTING TEST}

\subsubsection{Apparatus}

The present laboratory-scale apparatus (Fig. 6) allows treatability testing to be performed on surrogate wastes or small samples of authentic material (Del Cul et al., 1994). It also allows design improvements to be rapidly implemented in a developmental mode. The microwave applicator design has scaling laws that are well understood, and the performance of these systems can be extrapolated to full-scale systems (White, 1995).

The laboratory-scale system consists of a $3-\mathrm{kW}, 2450-\mathrm{MHz}$ microwave generator, a wave guide transmission system, a programmable power controller, and an in-beaker applicator as Fig. 6 shows. The applicator produces the $\mathrm{TM}_{01}$ mode within a commercially available 4-in.diameter (1.2-L volume) stainless steel beaker used to contain the waste. This mode was selected to provide uniform heating in the small vessel (the more complex $\mathrm{TE}_{01}$ mode may be selected for use in larger geometries). 


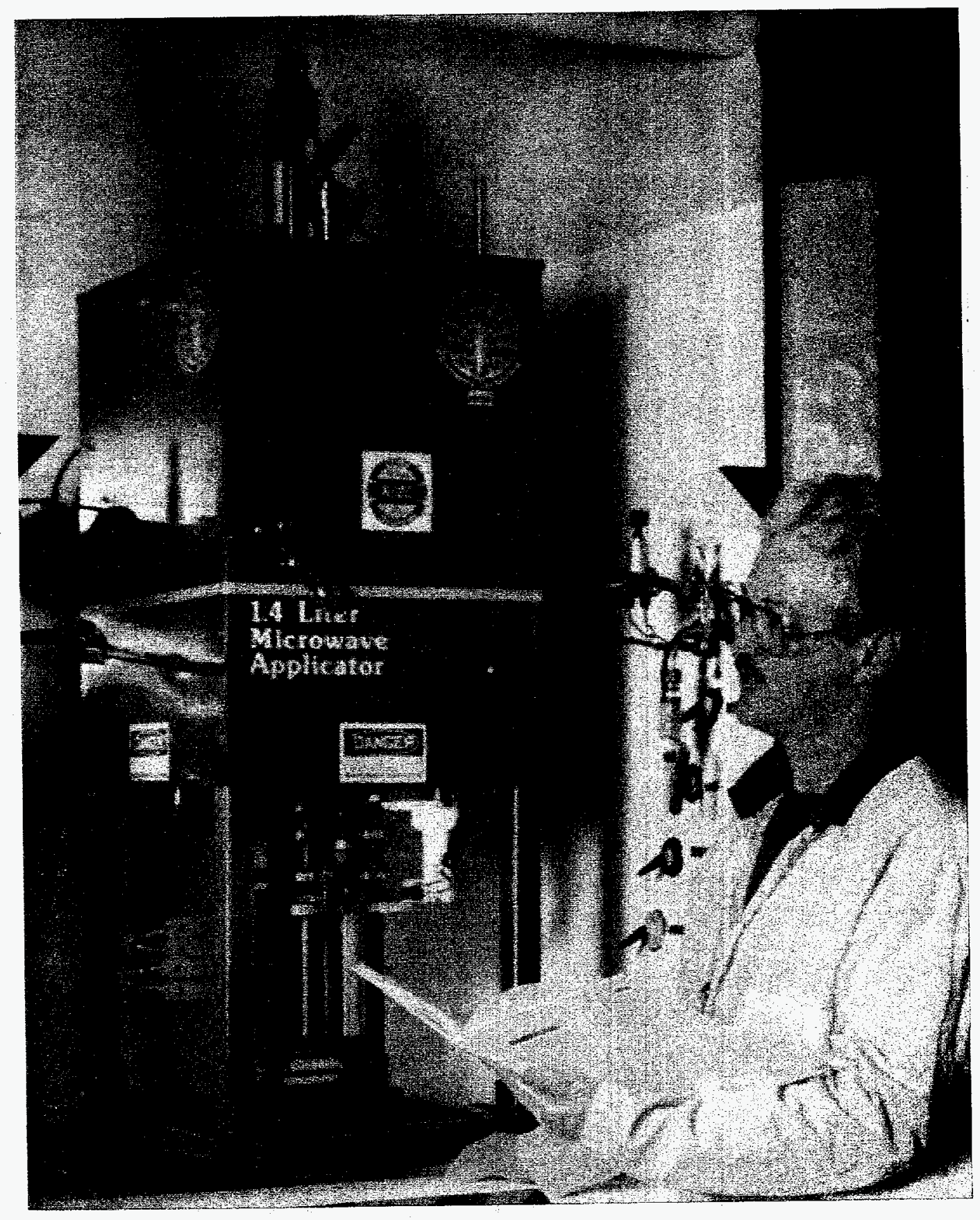

Fig. 6. Laboratory-scale microwave melting apparatus. 
The treatment progress was observed and continuously recorded through a color camera-TVVCR system. The entire testing apparatus is contained in a radiological hood. In order to monitor the progress of the heating process, three K-type thermocouples attached to the outer wall of the beaker were used to measure the "skin" temperature. The length of the microwave cavity can be continuously modified to account for changes in the waste volume during the drying/melting process. This adjustment minimizes the reflected microwave power, allowing the microwave heating system to maintain the maximum heating efficiency. The measured temperatures and forwarded and reflected microwave power were continuously recorded and displayed using an IBM-compatible personal computer equipped with data acquisition system.

\subsubsection{Glass Additives}

In order to melt or vitrify the waste at lower temperatures and to produce a densified and durable waste form, sometimes it is necessary to add glass additives to the waste. Depending on the glass constituents present in (or added to) the waste, the waste form may be a brick-like ceramic, a stone-like monolith, or an amorphous glass (Del Cul et al., 1994).

In this study, three types of glass additives were tested-a calcium-silicate system (WSS\#4-1), a calcium-borax-silicate system (WSS\#4-2), and a calcium-lithium-silicate system (WSS\#5-1, WSS\#5-2 and WSS\#6-1). All recipes were based on a nominal $~ 50 \%$ waste loading (oxides basis) except that WSS\#4-2 had a $\sim 35 \%$ waste loading. It is worth pointing out that calcite $\left(\mathrm{CaCO}_{3}\right)$, the predominant species in the sludge, is a major glass former. Lithium was considered as one of the fluxing and viscosity control reagents for performance evaluation because there is excess lithium hydroxide ( 23 million lbs) stored on the Oak Ridge Reservation DOE (1993). Some initial glass formulations were suggested by Dr. Carol Jantzen of the Savannah River Technology Center (C. Jantzen, personal communication to W.D. Bostick, April 21, 1995). However, the relatively high magnesia content of the waste (Table 1) presents some limitations, because $\mathrm{MgO}$ cannot readily substitute for $\mathrm{CaO}$ in soda-lime-silica glasses ( $\mathrm{MgO}$ may cause microcrystallization), and large quantities of $\mathrm{MgO}$ may cause borosilicate glasses to phase separate (C. Jantzen, personal communication to W. D. Bostick et al., February 30, 1996).

Fly ash from utility facilities consists of silica and metal oxides and is considered as a cheap glass additive. In Run WSS\#7-1, class-F fly ash supplied by American Fly Ash Company (in North Bend, Ohio) was used as the silica source. For comparison purposes, a test without any additives was also carried out (i.e., WSS\#5-3). 
In some formulations, natural (nonradiological) $\mathrm{Cs}$ and $\mathrm{Sr}$ were spiked onto the sludge surrogates. $\mathrm{CsCl}$ and $\mathrm{SrCl}_{2} \cdot 6 \mathrm{H}_{2} \mathrm{O}$ were used as spiking compounds. However, poor analytical detectability prevented any meaningful conclusion to be drawn regarding the fate of cesium in the waste forms.

\subsubsection{Test Procedures}

Experiments were carried out batch-wise. For each experimental run, a mixture of known amounts of surrogate and/or glass additives was prepared. For the series of tests using WSS\#4, tap water was added for mixing. The prepared mixture was then placed in a 1.2-L beaker and the power was set from 0.2 to $0.4 \mathrm{~kW}$ for initial heating and then slowly increased (to avoid boiling and arcing) until sludge melting was observed through the camera-TV-VCR system. During the experiment, a microwave detector was used to check microwave leakage and the length of the microwave cavity was modified by adjusting the hand crank to minimize the reflected microwave power. After the sludge had been completely melted for about $30 \mathrm{~min}$, the system was shut down. The glass or slag product was removed after it cooled to room temperature. The slag product was then subject to XRD analyses. Densities of slag products were also measured by the helium method.

\subsubsection{Experimental Results}

Figure 7 shows some representative waste forms. Both silicate-based and lithium-silicate-based glass additives (melts WSS\#4-1, WSS\#5s and WSS\#6-1) produced greenish, non-transparent, rather porous slag. Dark, glass-like, semi-transparent products were obtained by adding borax/silicate additives into the surrogate (e.g., melt WSS\#4-2). Different recipes, however, produced waste forms with similar densities $\left(\sim 2.7 \mathrm{~g} / \mathrm{cm}^{3}\right)$ and yielded significant volume reductions (about three- to fourfold) at apparent temperatures ranging from $728^{\circ} \mathrm{C}$ to $1034^{\circ} \mathrm{C}$. Fly ash does appear to be a viable additive and attainable volume reductions and consolidated waste form are impressive from the WSS\#7-1 results (vide infra). Without any additives, the surrogate (WSS\#5) was calcined to have an unconsolidated, flimsy waste form. Brief descriptions for the products from different formulations tested are summarized below:

1. No Additives

Run WSS\#5-3 was performed using no added reagents. The surrogate waste is silicon-deficient and the microwave-heated sample had a charred appearance (see Fig. 8). The resultant solids 

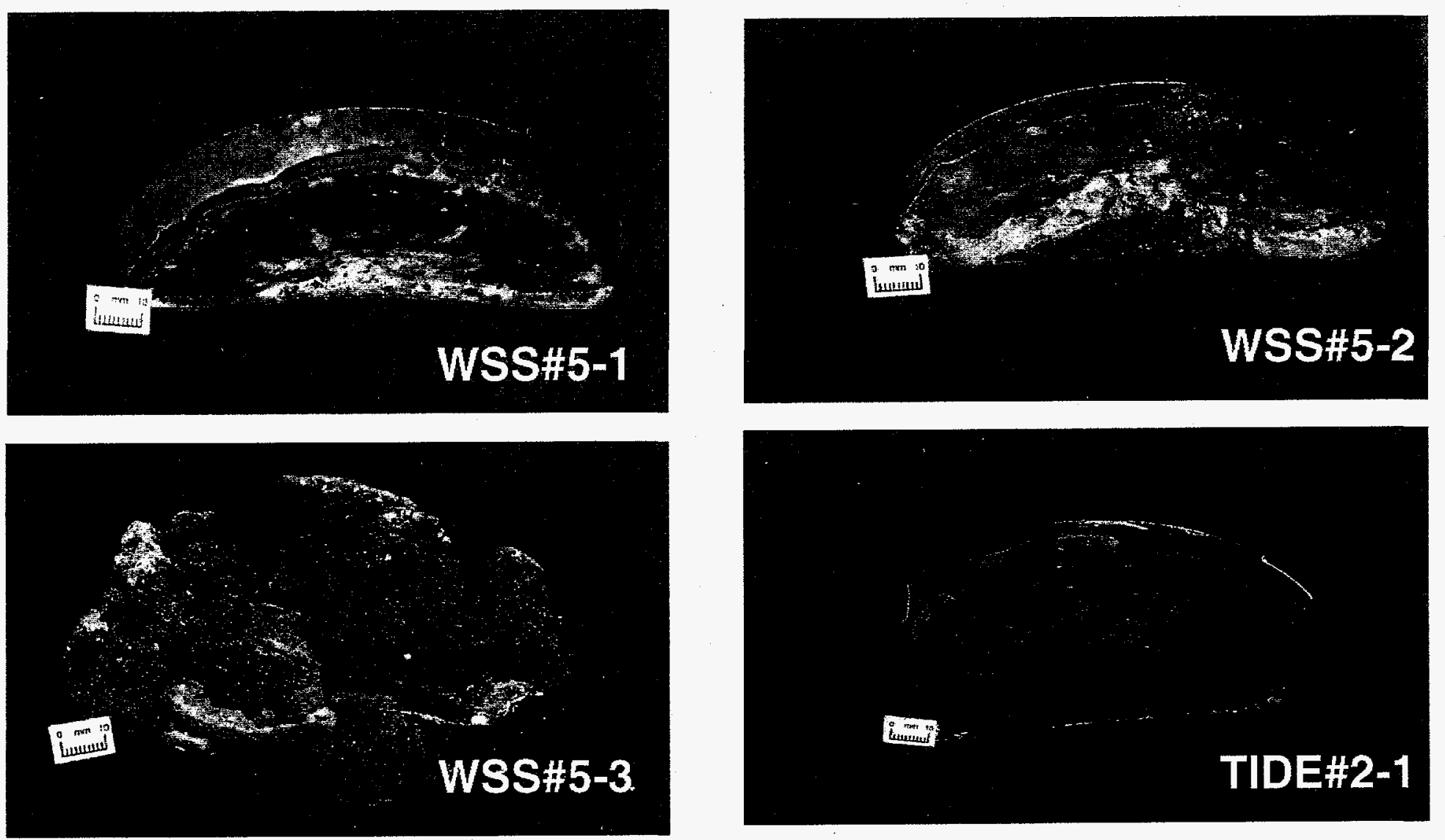

Fig. 7. Representative microwave melt products (see text for material descriptions). 
were friable and were not well consolidated. The maximum temperature recorded by the thermocouples attached to the crucible was $1164^{\circ} \mathrm{C}$.

2. Calcium-Silicate System

Run WSS\#4-1 used only perlite (a volcanic glass product, predominantly silica) as the additive reagent. The surrogate (WSS\#4) was produced by precipitating the reagent chemicals $\left(\mathrm{CaCl}_{2} * 2 \mathrm{H}_{2} \mathrm{O}, 462 \mathrm{~g} ; \mathrm{FeCl}_{3} * 6 \mathrm{H}_{2} \mathrm{O}, 26 \mathrm{~g} ; \mathrm{MgCl}_{2} * 6 \mathrm{H}_{2} \mathrm{O}, 174 \mathrm{~g} ; \mathrm{Al}\left(\mathrm{NO}_{3}\right) * 9 \mathrm{H}_{2} \mathrm{O}, 50 \mathrm{~g} ; \mathrm{SiO}_{2}\right.$, $50 \mathrm{~g}, \mathrm{Na}_{2} \mathrm{CO}_{3}, 265 \mathrm{~g}$ ) from aqueous solution. The resulting wet filtercake was collected by vacuum filtration and rinsed with tap water to remove excess soluble reagent (primarily sodium chloride and sodium nitrate, although some $\mathrm{Mg}(\mathrm{OH})_{2}$ also appeared to leach during the rinsing step). This process yielded a wet paste (density $\sim 1.3 \mathrm{~g} / \mathrm{cm}^{3}$ ), containing $44.6 \mathrm{wt} \%$ solids. The dried solids had a tamp density of $\sim 0.6 \mathrm{~g} / \mathrm{cm}^{3}$, and had a BET surface area of $19.5 \mathrm{~m}^{2} / \mathrm{g}$. The rheology of the wet surrogate filtercake is a fair representation of the authentic material. The wet surrogate paste was mixed with perlite and additional water (to enhance blending). Microwave power was controlled at $0.2-0.4 \mathrm{~kW}$ for initial heating and drying, then slowly increased to achieve melting. The maximum temperature recorded by the thermocouples attached to the crucible was $876^{\circ} \mathrm{C}$. The nominal waste loading (oxide basis) was $\sim 45 \mathrm{wt} \%$ The solidified product (a greenish slag-like consolidated mass) had a density of $\sim 2.7$, and represents a VR $\sim 2.74$.

3. Calcium-Lithium-Silica System

A series of runs were performed, using $\mathrm{LiOH}$ as an additive, based upon formulae suggested by Dr. Carol Jantzen of Westinghouse Savannah River Technology Co. Duplicate runs WSS\#5-1 and WSS\#5-2 used a solids blend of dried surrogate (39.13 wt \%), silica (43.03 wt \%), magnesium carbonate (5.22 wt \%) and lithium hydroxide (12.63 wt \%). After microwave heating, the nominal waste loading (oxide basis) was $\sim 50 \mathrm{wt} \%$. The maximum temperature recorded by the thermocouples attached to the crucible was $728^{\circ} \mathrm{C}$ (Run WSS\#5-1) and 1034 ${ }^{\circ} \mathrm{C}$ (Run WSS\#5-2). The solidified product was a somewhat porous greenish-brown slag-like material, representing a nominal MR between $\sim 4: 11$ and 4.19 and a VR of between 2.70 and 2.73 .

4. . Borosilicate System

The borosilicate glass system is a relatively robust system for incorporating sludge waste 
(Sprenger and Eschen, 1993; Del Cul et al., 1994). Run WSS\#4-2 was performed using perlite as the silica source, whereas run WSS\#7-1 substituted ASTM Class F fly ash (supplied by American Fly Ash Co., North Bend, $\mathrm{OH}$.

Run WSS\#4-2 utilized wet surrogate filtercake, perlite, and borax. The maximum temperature recorded by the thermocouples attached to the crucible was $787^{\circ} \mathrm{C}$. On an oxide-basis, the final (glassy) waste form contained the equivalent of $\sim 34.2 \mathrm{wt} \%$ waste, $52 \mathrm{wt} \% \mathrm{SiO}_{2}$, and 13.8 wt $\% \mathrm{Na}_{2} \mathrm{~B}_{4} \mathrm{O}_{7}$. Using XRD analysis, we identified that the vitrified product of WSS\#4-2 is predominantly amorphous glass and that the very small amount of associated unconsolidated powder has a major crystalline phase of wollastonite $\left(\mathrm{CaSiO}_{3}\right)$ with minor gehlenite $\left(\mathrm{Ca}_{2} \mathrm{Al}_{2} \mathrm{SiO}_{7}\right)$. At a conservative $34.2 \mathrm{wt} \%$ waste loading and a waste form density $\sim 2.71 \mathrm{~g} / \mathrm{cm}^{3}$, this yields a VR $\sim 3.31$.

Applying the same recipe as WSS\#4-2, a series of parallel studies were conducted in an electrical resistance furnace under temperatures between 900 and $1150^{\circ} \mathrm{C}$. In the experiment, a 50-ml ceramic crucible half-filled with prepared sludge was heated to the designated temperature in the furnace and kept for one hour. The resultant products had similar appearance as the one from microwave heating experiment but had a rather lower density of $2.44 \mathrm{~g} / \mathrm{cm}^{3}$.

For run WSS\#7-1, ASTM Class F fly ash was used as the silica source. The composition of the fly ash (by SSQ-EDS estimate) was: $\mathrm{Al}_{2} \mathrm{O}_{3}, 27.24 \mathrm{wt} \% ; \mathrm{SiO}_{2}, 53.22 \mathrm{wt} \% ; \mathrm{SO}_{3}, 0.93 \mathrm{wt} \%$; $\mathrm{K}_{2} \mathrm{O}, 2.51$ wt $\%, \mathrm{CaO}, 2.44$ wt $\%, \mathrm{TiO}_{2}, 1.03$ wt \%, $\mathrm{FeO}, 11.33 \mathrm{wt} \%$, and $\mathrm{CuO}, 0.66$ wt \%. On an oxide basis, the final waste form contained the equivalent of $\sim 49.2 \mathrm{wt} \%$ waste, $40.1 \mathrm{wt} \%$ ASTM Class F fly ash, and $10.7 \mathrm{wt} \% \mathrm{Na}_{2} \mathrm{~B}_{4} \mathrm{O}_{7}$. The maximum temperature recorded by the thermocouples attached to the crucible was $903^{\circ} \mathrm{C}$. The (slag-like) waste form, pictured in Fig. 8, was dark brown, with noticeable porosity. The density of the waste form, based upon "Archimedes" method" for volumetric displacement (which includes the contribution due to porosity), was $2.49 \mathrm{~g} / \mathrm{cm}^{3}$, yielding a VR $\sim 4.98$.

In summary, microwave melting is a promising process to treat the ORNL water softening sludge by showing the credits of significant volume reductions (three- to fivefold) and a durable final waste form (with appropriate additives). This study did not provide the optimization of process parameters such as operation temperature, heating rate, and glass additives; but it does establish the 
figure of merit for microwave melting technology.

\subsection{CONTINUOUS MICROWAVE MELTING}

Dr. T. L. White et al. (December, 1995) has recently demonstrated a prototype 915-MHZ, $75-$ $\mathrm{kW}$ continuous-feed microwave melter, using ORNL filtercake surrogate in a borosilicate matrix. Feed to the melter was a blend of $50 \mathrm{wt} \%$ dry surrogate, $25 \mathrm{wt} \%$ silica, and $25 \mathrm{wt} \%$ borax. Nominal waste loading in the waste form was $45 \mathrm{wt} \%$ (as oxides), which (together with a waste form density of $2.7 \mathrm{~g} / \mathrm{cm}^{3}$ ) represents a VR $\sim 4$. I. In this testing, sand, diatomaceous earth, and Class F fly ash were used interchangeably as the silica source, each producing a dense, nonporous glass waste form. The melter design incorporates an overflow drain for casting glass product into a metal container (see Fig. 8). Between melting campaigns, a hold-up volume of glass from the previous campaign was used as a "cullet" to facilitate the melting operation, because coupling of the microwave energy to remelt the glass was more efficient than coupling with the dry chemicals used to form the glass. Once a molten phase was created, dry chemicals were continuously fed to the melter. Figure 9 illustrates representative glass castings.

Also illustrated is a light-colored silicate phase, predominantly cristobalite (a silica polymorph normally formed at relatively high temperatures $\left.\gg 1200^{\circ} \mathrm{C}\right)$ and diopside $\left(\mathrm{CaMgSi}_{2} \mathrm{O}_{6}\right)$, that was removed from the melter at the end of several melting campaigns. This silicate-rich phase was somewhat less dense than the waste glass phase (densities $\sim 2.6$ and $2.7 \mathrm{~g} / \mathrm{cm}^{3}$, respectively), and likely represents a devitrification reaction product and phase-separation, accelerated by the presence of magnesium ion, because the skin temperature of the (Inconel alloy) melter never exceeded $\sim 1100^{\circ} \mathrm{C}$ at any time during operation.

\subsection{MICROWAVE MELT MINERALIZATION}

Investigators at EET Corp. (Knoxville, Tennessee) have focused on the use of microwave energy to melt surrogate waste with minimal additives to produce an assemblage of silicon-deficient crystalline minerals. Whereas formation of crystalline material is generally undesirable for cast glass in conventional vitrification due to an adverse effect upon melt viscosity, etc., formation of an assemblage of mutually compatible crystalline minerals may yield a durable waste form with an exceptionally high waste loading (White and Toor, 1995; Ewing et al., 1995).

The initial waste form evaluated from use of this concept ("EET -2 ") was prepared from a 


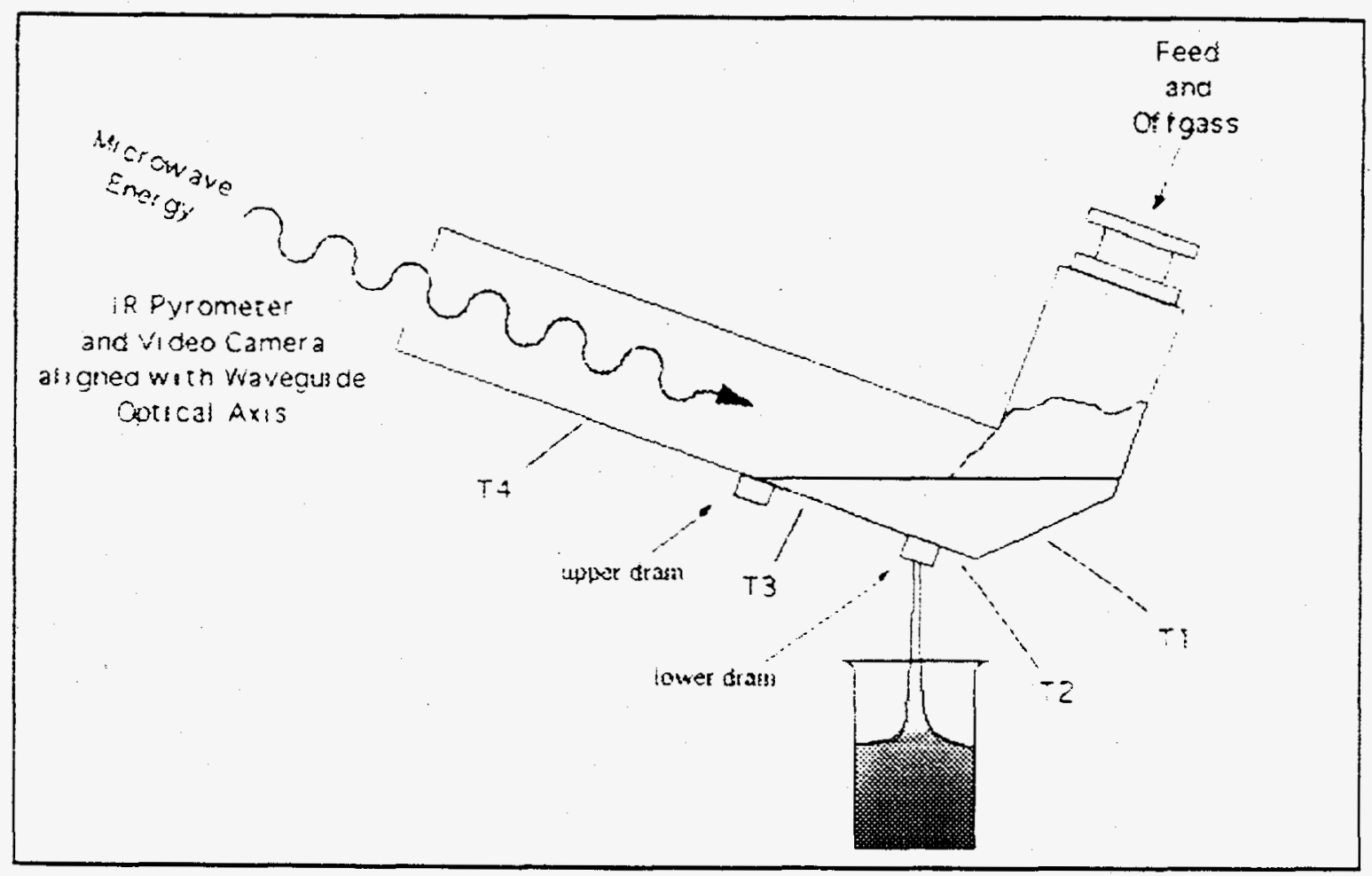

Fig. 8. Continuous-feed microwave melting apparatus (courtesy of T. L. White). 


\section{Glass}
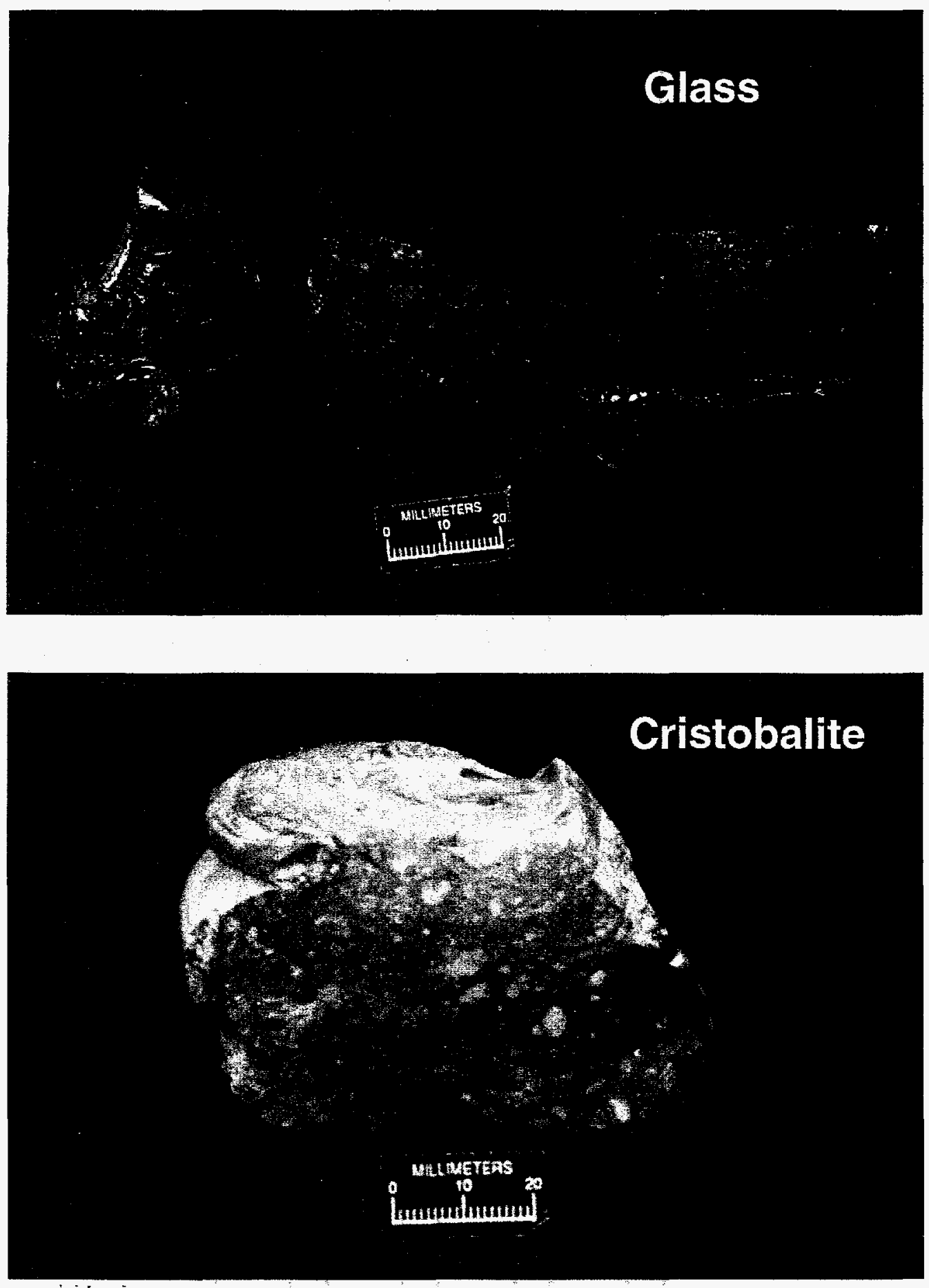

Fig. 9. Waste forms from continuous-feed microwave melting apparatus. 
mixture of $80 \mathrm{wt} \%$ surrogate dried solids ("TIDE-2"), $15 \mathrm{wt} \%$ silica (as diatomite) and $5 \mathrm{wt} \%$ waste iron dust (magnetically separated spent iron shot blasting medium). This mixture was placed in an alumina crucible and was melted using microwave energy. Although no direct temperature measurements were recorded, the melt temperature was estimated to be in the range of 1300 to $1500^{\circ} \mathrm{C}$. The solidified material had a computed waste loading (oxide basis) of $74.1 \mathrm{wt} \%$ and a density of $3.097 \mathrm{~g} / \mathrm{cm}^{3}$, yielding an estimated VR of $\sim 7.66$. The solidified mass was predominantly crystalline; by $\mathrm{XRD}$, the predominant crystalline phases in the assemblage were merwinite $\left(\mathrm{Ca}_{3} \mathrm{Mg}\left(\mathrm{SiO}_{4}\right)_{2}\right)$, akermanite $\left(\mathrm{Ca}_{2} \mathrm{MgSi}_{2} \mathrm{O}_{7}\right)$, magnetite $\left(\mathrm{Fe}_{3} \mathrm{O}_{4}\right)$, and quartz $\left(\mathrm{SiO}_{2}\right)$, plus addititional minor unidentified phases.

A large-scale melt was performed ("EET-6"), using surrogate "EET-DL" and beach sand instead of the diatomite, and also using an alternate source of waste iron reagent. The melt was performed in a nickel-plated iron container, using microwave energy from a 3 to $4 \mathrm{~kW}$ source. The mineral phases identified in the waste form were akermanite $\left(\mathrm{Ca}_{2} \mathrm{MgSi}_{2} \mathrm{O}_{7}\right)$ and monticellite $\left(\mathrm{CaMgSiO}_{4}\right)$, with trace magnetite $\left(\mathrm{Fe}_{3} \mathrm{O}_{4}\right)$. Figure 10 is a polarized light image of a thin section of a wasteform produced by microwave melt mineralization; the dark field represents glass and amorphous phases, whereas the colored images represent various crystalline phases. The resultant waste form had noticeable porosity (probably due to incomplete degassing from the decomposition of carbonate). The skeletal density of the waste form was determined to be $3.16 \mathrm{~g} / \mathrm{cm}^{3}$, which at a waste loading of $\sim 72 \mathrm{wt} \%$ (oxide equivalent) represents a VR $\sim 7.73$. These results are similar to the results of the small-scale crucible melt. 


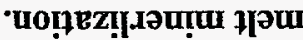

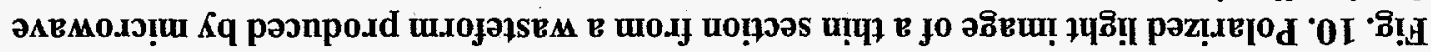

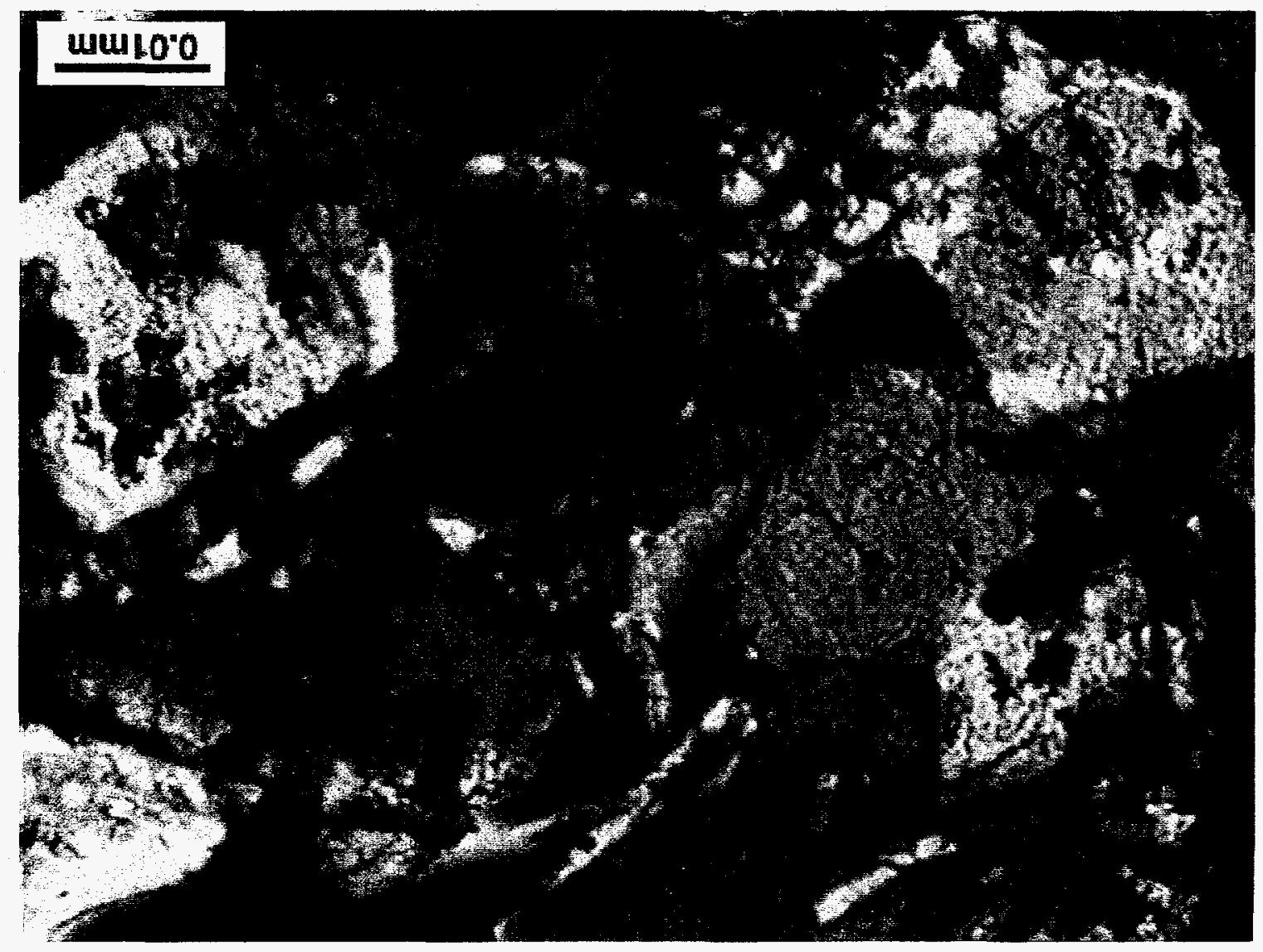




\subsection{OTHER VITRIFICATION}

The U.S. EPA has recognized vitrification as Best Demonstrated Available Technology for many kinds of hazardous and/or radiologically contaminated waste (EPA, 1992). It should be mentioned that the melter technologies demonstrated using microwave heating could also be performed with the use of other vitrification systems, including conventional joule-heating (Freeman et al., 1995).

A large-scale, portable joule-heat vitrification system, developed in cooperation with Westinghouse Savannah River Co., LMES, and EnVitCo, Inc., is scheduled to be located at the Oak Ridge K-25 Site in 1996. In preliminary testing with surrogate Y-12 WETF and K-25 Pond Waste sludges (see Bostick et al., 1994 for surrogate formulation), the throughput of the Transportable Vitrification System was $\sim 112 \mathrm{lb}$ glass product/h. Benchmarking to this throughput and assuming a fairly conservative waste loading of $\sim 45 \mathrm{wt} \%$ waste oxide and a glass density of $\sim 2.7 \mathrm{~g} / \mathrm{cm}^{3}$, this would be equivalent to processing $\sim 0.6 \mathrm{drum} / \mathrm{h}$ of the as-stored $\mathrm{ORNL}$ wet filtercake. 


\section{CONCLUSIONS}

The results of microwave melting experiments show that it is a promising process to treat the ORNL water softening sludge. The resultant volume reductions were significant (three to fivefold) and a dense, solidified waste form was produced with the use of appropriate glass-forming additives (i.e., silicate, sodium borax, lithium hydroxide, fly ash, etc.). The results from small batch melts were duplicated using a microwave continuous melter developed by T. L. White of Fusion Energy Division, ORNL, which suggests that microwave heating is a viable technology to treat the filtercake in a full-scale operation mode.

The preliminary results of microwave melt mineralization, performed by EET Corporation, are encouraging, achieving a volume reduction of $\sim 7.7$ with the use of surrogate. It may be advantageous to couple this waste densification process with conventional calcination to avoid waste form porosity due to the evolution of carbon dioxide during melting. It may also be possible to combine additives with the hot calciner product to take advantage of the thermal inertia of the calciner output in order to minimize energy consumption during the continuous-feed in-container microwave densification process.

Calcination of solids in a rotary kiln is a mature process. Calcination of the filtercake from $\mathbf{8 5 0}$ to $900^{\circ} \mathrm{C}$ yielded a VR of 2.53 and an MR of 1.61. Similar results were found from surrogate tests. Followed by the compaction at 4500 psi, the VR was increased to 4.18 , but the compressed form is not dimensionally stable. Addition of paraffin helped consolidate fines and yielded more stable form, and resulted in overall VR and MR of 3.5 and 3.1, respectively. The calcination/compaction/waxing process is likely to be a viable near-term option for filtercake treatment because of its immediate availability and comparable volume and mass reductions. The final waste form would not have the durability of glass or slag produced from vitrification processes, however. It is also necessary to design equipment capable of effectively mixing the calcines and the binding agents.

The TIDE process does not provide competitive volume reduction (less than twofold) to stabilize the ORNL filtercake, as compared to microwave melting or the calcination/compaction/waxing process.

This study showed, by testing small amounts of the filtercake surrogates, the VES process can attain a waste form of solid monolith, but overall VR was modest. In terms of cesium volatilization, the VES process is more favorable than microwave melting and rotary kiln calcination due to its much lower operating temperature. 


\section{REFERENCES}

Arnold, J. L. and Diel, B. N., "Use of Phoenix Ash Technology for Hazardous and Radioactive Nitrate-Salt Wastes," p. 320 in Extended Abstracts, Emerging Technologies in Hazardous Waste Management VII, Atlanta, Georgia, September 17-20, 1995.

Aulbaugh, R. And Hawk, G., "High Temperature High Vacuum Rotating Mobile Retort for Recovery of Mercury and Removal of Organic Chemicals," pp. 723-727 in Proceedings of 1995 International Incineration Conference, Bellevue, WA, May 8012, 1995.

Autry, V.R., South Carolina Department of Health and Environmental Control, Division of Radioactive Materials Licensing and Compliance, Official Correspondence to W.B. House, Chem-Nuclear Systems, Inc., Corporate Director of Licensing, July 30, 1992.

Baltpurvins, K.A., Burns, R.C., Lawrence, G.A., and Stuart, A.D., 1996, "Effect of pH and Anion Type on the Aging of Freshly Precipitated Iron(III) Hydroxide Sludges," Environ. Sci. Technol., 30, 939.

Bescher, E. P., Kao, Y. and Mackenzie, J. D., "Microwave sintering of ashes," paper presented at the 84th Annual Meeting of AWMA, Vancouver, Canada, June 16-21, 1991.

Bostick, W.D., D.P. Hoffmann, R.J. Stevenson, A.A. Richmond, and D.F. Bickford, 1994, "Surrogate Formulations for Thermal Processing of Low-Level Mixed Waste. Part IV: Wastewater treatment Sludges," DOE/MWIP-18.

Burger, L. L., "A Chemical Basis for the Partitioning of Radionuclides in Incinerator Operations," PNL10364/UC-601, Pacific Northwest Laboratory, January 1995.

Del Cul, G. D. et al., "Solidification of Waste Sludges Using Microwave Heating," Proceedings of 1994 International Incineration Conference, pp. 615-620, Houston, TX, May 9-13, 1994.

Ewing, RC., W. Lutze, W.J. and Weber, 1995, Crystalline Ceramics: Waste Forms for the Disposal of Weapons Plutonium, CONF-9505238-2.

Freeman, C.J., G.P. Abrigo, P.J. Shafer, and R.A. Merrill, Literature Review of Arc/Plasma, Combustion, and Joule-Heated Melter Vitrification Systems, Pacific Northwest Lab., July 1995.

Gibson, L. V., Jr., W. H. Hermes, W. D. Bostick, D. P. Hoffmann, D. P. Schaefferkoetter, J. E. Dunn, Jr., and F. Perez, "Partitioning of Strontium and Cesium in the TSCA Incinerator," K/ASD-033, Martin Marietta Energy Systems, Inc., October 1994.

Lee, Hom-Ti, J.A.D. Stockdale, W.D. Bostick, and T.C. Ho, 1994, "Selection of Radiological Surrogates for Thermal Treatment of Low-Level Waste," paper presented at 1994 AIChE National Meeting, Denver, Colorado, August 14-17, 1994.

Lomenick, T.F. (ed.), "Proceedings of the Workshop on Radioactive, Hazardous, and/or Mixed Waste Sludge Management," CONF-901264, Martin Marietta Energy Systems, Inc., January 1992.

Miller, T., Scientific Ecology Group, Inc., personal communication to W. D. Bostick, Martin Marietta Energy Systems, Inc. 
Morgan, I. L. and Bostick, W. D., "Performance Testing of Grout-Based Waste Forms for the Solidification of Anion Exchange Resins," Hazardous Wastes, Standard Technical Publication 1123, ASTM, Philadelphia, PA, 1992.

Petersen, R. D. and Sprenger, G. S., "Microwave waste processing technology overview," Proceedings Waste Management'93.

Ross, W.A., M. R. Elmore, C.L. Warner, L.J. Wachter, W.L. Carlson, and R.L. Devries, "Locations, Volumes, and Characteristics of DOE's Mixed Low-Level Wastes," in R.G. Post and M.E. Wacks (eds.), Waste Management '92, Symposium on Waste Management at Tucson, Arizona, March 1-5, 1992, pp. 1127-1135.

Spence, R. D., Trotter, D. R., Francis, C. L., and Morgan, I. L., "Stabilization/Solidification of TSCA Incinerator Ash," pp. 633-638 in Proceedings of International Incineration Conference, Houston, Texas, May 9-13, 1994.

Sprenger, G.S., and V.G. Eschen, 1993, "Critical Operating Parameters for Microwave Solidification of Hydroxide Sludge," pp. 7.1.1-7.1.5 in Proceedings of Second International Symposium on Mixed Waste, Baltimore, Maryland, August 17-20, 1993.

Tai, C.Y., and P.C. Chen, 1995, "Nucleation, Agglomeration, and Crystal Morphology of Calcium Carbonate," AIChE Journal, 41(1), 68.

U.S. Department of Energy, April 1993, Environmental Assessment for the sale of excess lithium hydroxide stored at the Oak Ridge K-25 Site and the Portsmouth Gaseous Diffusion Plant (DOE/EA-0855).

U.S. Environmental Protection Agency, May 1992, Handbook: Vitrification Technologies for Treatment of Hazardous and Radioactive Waste, EPA/625/R-92/002.

Walker, T. W., "Special Project (380) Sampling Results," Interoffice Memorandum to C. B. Scott, Martin Marietta Energy Systems, Inc., August 4, 1993.

Werner, Paul M., Diversified Technologies Services, Inc., personal communication to Bostick, W. D., Martin Marietta Energy Systems, Inc., May 4, 1995.

White, T. L., "Final Report: Heat Transfer Enhanced Microwave Process for Stabilization of Liquid Radioactive Waste Slurry," CRADA/ORNL-93-0190, March 1995.

White, T.L., W.D. Bostick, C.T. Wilson, and C.R. Schaich, December 1995, "Design of Microwave Vitrification Systems for Radioactive Waste," Presented at the Electric Power Research Institute Conf. on Vitrification of Low-Level Waste-The Process and Potential, San Antonio, Texas, December 5-6, 1995.

White, T.J., and Toor, I.A., 1995, "Synthetic Mineral Immobilization Technology for the Stabilization of Incinerator Ashes," pp. 355-360 in Proceedings of 1995 International Incineration Conference, Bellevue WA, May 8-12, 1995. 


\section{DISTRIBUTION}

Internal

LMES

1. J. B. Berry

2. A. Blier

3. D. A. Bostick

4.-7. W. D. Bostick (3)

8. T. A. Bowers

9. T. B. Conley

10.-15. G. R. Cunningham (5)

16. L. R. Dole

17. F. A. Evans

18. T. M. Gilliam

19. D. F. Hall

20. W. H. Hermes

21. C. M. Kendrick

22. T. E. Kent

23. R. R. Kimmitt

24. G. R. Larson

25. R. J. Lauf

26. H. T. Lee

27. D. L. Mason

28. A. J. Mattus

29.

30.

31.

32.

33.

34.-37. A. S. Quist (3)*

38. S. M. Robinson

39. T. L. Sams

40. T. F. Scanlan

41. D. P. Schaefferkoetter

42.

43.

44.

45.

46.

47.

48.

50.
C. H. Mattus

B. C. McClelland

L. J. Mezga

C. J. Miller

A. E. Pasto

C. B. Scott

M. J. Shelton

J. L. Shoemaker

R. D. Spence

R. J. Stevenson

M. W. Tull

F. R. VanRyn, Jr.

T. L. White

External

51. G. Abotsi, Clark Atlanta University, 223 J. P. Brawley Drive, S. W. , Atlanta, GA 30314.

52. A. J. Beck, Jr., EET Corp., 830 Corridor Park Boulevard, Knoxville, TN 37932.

51. C. M. Jantzen, Savannah River Laboratory, Post Office Box 616, Aiken, SC 29802.

52. C. Jensen, Diversified Technologies Services, 2680 Westcott Boulevard, Knoxville, TN 37931.

53. T. Miller, Scientific Ecology Group, Inc., 1560 Beark Creek Road, Post Office Box 2530, Oak Ridge, TN 37831.

54. T. Overcamp, Clemson Research Park, Clemson, SC 29634.

55. R. Petersen, EET Corp., 830 Corridor Park Boulevard, Knoxville, TN 37932.

56. J. Whitehouse, Savannah River Laboratory, Post Office Box 616, Aiken, SC 29802.

*Two copies to the Office of Scientific and Technical Information 
- 


\section{APPENDIX A}

Options for Immobilization of ORNL Process Waste Treatment Facility Water Softening Sludge, D. E. Beck et al., December 1994 



\section{Internal Correspondence}

December 5, 1994

MARTIN MARIETTA ENERGY SYSTEMS, INC.

To: G. R. Cunningham

Options for Immobilization of ORNL Process Waste Treatment Facility Water Softening Sludge

Enclosed is a review, as requested, of viable options for immobilizing the calcium carbonate-based Water Softening Sludge (WSS) from ORNL's Process Waste Treatment Facility (PWTF). It includes a literature survey and some vendor interviews. The enclosed review should give you a better perspective of the strengths and weaknesses of the various proposed treatment options, including their performance against disposal criteria.

Attached are copies of these key references:

a draft of Evaluation of Interim and Final Waste Forms for the Newly-Generated Liquid LowLevel Waste Flowsheet, by G. M. K. Abotsi, D. A. Bostick, and W. D. Bostick (to be published),

the memo from C. E. Jensen, President of Diversified Technologies Services, Inc., to W. D. Bostick, describing their vinyl ester styrene (VES) process,

report \#ES/ER/TM-109, T. L. Sams, R. C. Jones, R. J. Sams, Evaluation of Potential Disposal Sites for Environmental Restoration Waste Streams, and

The Technology Evaluation Data Sheets for Technology Logic Diagram, Pond Waste Management Alternatives Studies, ed. R. L. Fellows, et al.

If others on the distribution list would like copies of any of these references, please contact me.

Bill has been in touch with a local vinyl ester styrene (VES) process vendor. An on-site demonstration of VES to immobilize WSS may be possible in the near future. In addition, the procurement bid package, prepared by the Savannah River Laboratory for their M-area sludge, may be useful to you, should you consider privatization. We can request a copy of this document from Dr. Jantzen, if you would like.

Please let us know how else we can assist you.

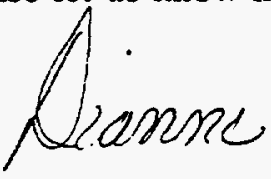

Dianne Beck (4-0706)
cc (w/o att.):
W. D. Bostick
T.L. Sams
J. L. Shoemaker
C. M. Jantzen
G. M. K. Abotsi
T. E. Kent
A. J. Mattus 



\title{
OPTIONS FOR TREATMENT/STABILIZATION OF CARBONATE-BASED WATER SOFTENING SLUDGE (WSS)
}

\author{
Prepared by: D. E. Beck ${ }^{1}$, J. L. Shoemaker ${ }^{1}$, and W. D. Bostick ${ }^{1}$ \\ Contributors: A. J. Mattus ${ }^{2}$, T. L. Sams ${ }^{3}$, and G. M. K. Abotsi' \\ 1 Technical Division, K-25 Site, Oak Ridge, TN \\ 2 Chemical Technology Division, Oak Ridge National Laboratory, Oak Ridge, TN \\ ${ }^{3}$ Environmental Restoration Program, Martin Marietta Energy Systems, Oak Ridge, TN \\ 4 Department of Chemistry, Clark Atlanta University, Atlanta, GA
}

\begin{abstract}
Water softening sludge (filter cake) generated at ORNL and currently held in interim storage at ORNL and the K-25 Site must be treated and/or stabilized and placed in safe storage or disposal; there are more than 400055 -gal. drums of this sludge stored and it is being generated at a rate of approximately 60055 -gal. drums per year. The dewatered sludges are classified as non-RCRA, lowlevel wastes. Objectives in preparing this sludge for disposal include 1) volume reduction, 2) radionuclide stabilization, and 3) elimination of free liquid. After reviewing the options, it is recommended that microwave sintering and vendor solidification in vinyl ester styrene (VES) be investigated, and that sample grout forms be prepared as a basis for comparison.
\end{abstract}

\section{INTRODUCTION}

Water softening sludge (WSS), generated by ORNL's Process Waste Treatment Plant (PWTP), Building 3544, must be treated, stabilized, and placed in safe storage/disposal. An annual processing of about 35,000 gallons, using mobile equipment, is envisioned. The dewatered sludges are classified as non-RCRA, low-level wastes. At this time, it is expected that the stabilized sludges will be placed in B-25 boxes inside concrete vaults on the Interim Waste Management Facility (IWMF) pads at ORNL's SWSA-6. Disposal or long-term storage at the IWMF demands the lowest achievable volume, because of space constraints. This report provides an overview of the various treatment/stabilization methods, using a review of the literature, vendor interviews, and subject specialist knowledge, to identify the most feasible WSS waste processing and stabilization methods.

Over 4000 drums of WSS are now stored at ORNL and at K-25, and an additional 600 drums per year are generated. From the stored drums, gamma spectroscopic analyses of 10 archived WSS samples showed Cs- 137 levels ranging from $1.4 \mathrm{E}+02$ to $73.8 \mathrm{E}+02 \mathrm{pCi} / \mathrm{g}$. Strontium -90 analysis results ranged from $1.3 \mathrm{E}+04$ to $9.9 \mathrm{E}+04 \mathrm{pCi} / \mathrm{g}$ (currently, on-line sludge characterization is employed, but the 4000 drums were generated prior to the start of this program).

Integral to preparation of this immobilization technology assessment was a search of the literature for inform ation on sludges, immobilization, grout, bitumen, volume reduction or increase, radioactivity/cesium leaching, and other relevant parameters. The initial on-line literature search on 
immobilization (with and without including the words grout, cement, or concrete) of calcium carbonate sludges failed to yield useful references. Searches for information on radioactive (and, specifically, cesium) leaching from waste forms were more successful. The literature searches were largely concentrated on bitumen stabilization, since we have more in-house knowledge and capabilities with the other waste forms (grout, glass/ceramic) or can more easily obtain information from local contacts (polymer/NES)

\section{GENERAL PERFORMANCE CRITERIA}

The waste must be conditioned to meet anticipated Waste Acceptance Criteria (WAC) for projected disposal scenarios; this may be site-specific. An overview of several off-site disposal options has been presented by Sams and co-workers: ${ }^{1,2}$

Envirocare of Utah, Inc.

Currently, Envirocare is the only site approved for disposal of mixed waste; since the WSS is not a mixed waste, this option may not be applicable, although they do indicate that they may accept low activity radioactive waste, including byproduct, source, and special nuclear material. Acceptable isotopes and their limits include: Cs-134 (1.2E+03 pCi/g), Cs-137 (5.6E+02 pCi/g), and Sr-90 $(2.0 \mathrm{E}+04 \mathrm{pCi} / \mathrm{g})$. Waste qualification includes: complete low-activity profile (EC-0200); complete physical properties form (EC-0500); complete radiological evaluation (EC-0650); soil pH/paint filter liquids test; analysis for $\mathrm{HCN}, \mathrm{H}_{2} \mathrm{~S}, \mathrm{TCLP}$ ( 8 metals $/ 32$ organics); and gamma spectroscopy. There are currently no requirements for waste form compressive strength; indeed, monolithic waste forms may have to be crushed for emplacement. Nonstabilized shudge may be acceptable if it meets other criteria, including the requirement for no free liquid -- this may make disposal of dried sludge possible, although the "calcined" sludge will be water-reactive and the constituents more readily leachable. $^{3}$

\section{Hanford Site}

The Hanford Site, according to Sams, may be a potential disposal site, although only stabilized waste forms are acceptable. Again, volume reduction is important, since estimated disposal costs (not including analytical documentation, packageing, and transportation) are $\$ 150-\$ 200 / \mathrm{ft}^{3}$ at Hanford and $\$ 40-\$ 80 / \mathrm{ft}^{3}$ at Envirocare.

\section{Nevada Test Site}

The Nevada Test Site may represent an option for off-site disposal in the future, although current permitting imposes certain restrictions. The only specific radionuclide requirement is that the LLW contain transuranic elements at less than $100 \mathrm{nCi} / \mathrm{g}$. Other requirements include: no listed or characteristically hazardous waste (as defined in 40 CFR 261); $<0.5 \%$ (v/v) free liquids; particulates immobilized so that the waste package contains $<1 \%(w / w)$ particulates with diameter $\left(d_{p}\right)<1$-um or $15 \%(w / w)$ with $d_{p}<200-u m$; and no PCB or pyrophorics, etc.

Figure 1 (from Sams, et al, 1994) is a matrix of waste streams and compatable disposal sites.

General waste form performance "guidelines" have been proposed by the U.S. Nuclear Regulatory Commission (NRC) and are summarized in Table 1. The ANS-16.1 Leachability Index (LI) is a parameter that characterizes the resistance of a solidified waste toward release of radioactive species; it is defined as the negative logarithm of the effective diffusivity coefficient $\left(D_{e}, \mathrm{~cm}^{2} / \mathrm{s}\right)$ for the 


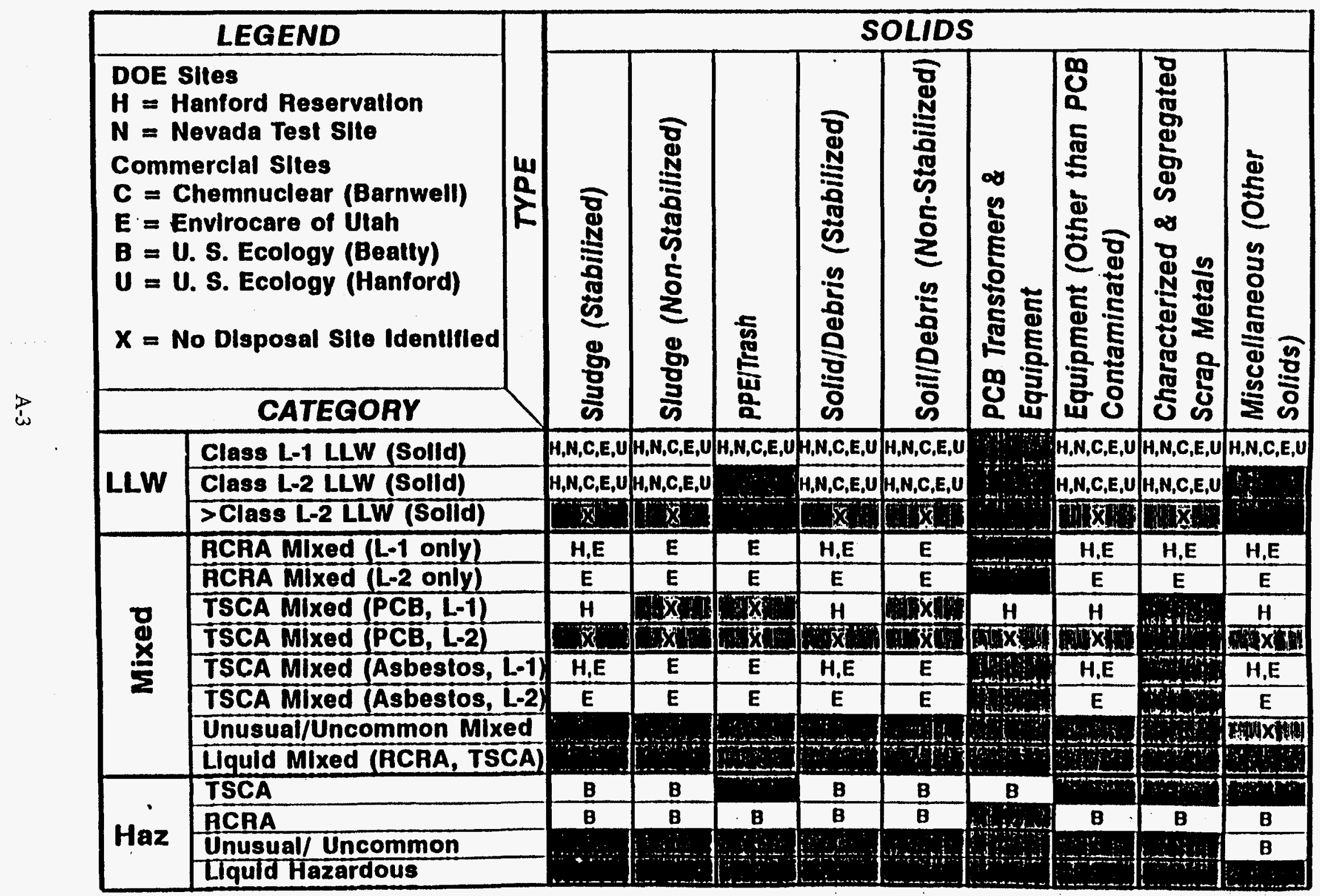


constituent of concern. Large values of LI correspond to low leaching rates, and the NRC criterion is LI $>6$. Additional waste form performance criteria and testing methods have recently been proposed by DOE-sponsored investigators E. M. Franz, et al. ${ }^{4}$ This text includes a good overview of applicable regulations for mixed waste.

\section{CEMENT GROUT}

Cement grout is a mixture of Portland cement and other materials such as blast furnace slag, fly ash, and lime. Additives are employed as necessary for reaction with and stabilization of specific components of the waste in question. Grouting has been used for a number of years as a waste stabilization matrix, and is often the preferred option because of its ability to bond chemically (depending on its formulation) with specific radionuclides, thus preventing their migration and leaching. Cement stabilization is a proven technology that has been widely used for treating both radioactive and RCRA wastes, with good results. It uses readily available, standard, off-the-shelf materials and equipment and is relatively inexpensive. Large companies with good track records offer grout as their preferred method of treatment. It is well suited to wet sludges such as the WSS material, and the resulting final waste form is easily handled, stacked, and stored. However, significant volume increases may result.

Generally, the physical performance of grout wasteforms well surpasses NRC requirements (see Table 1). Tests of cement wasteforms containing LLW incinerator ash showed compressive strength of 1400 psi and a leach index of 7.' In other tests, cement wasteforms prepared with calcium carbonatecontaining sludge showed compressive strength of 961 psi, still well above NRC requirements, ${ }^{6}$ although cement-based stabilization has received certain criticism from the NRC (Workshop Commission, 1989) and the DOE. ${ }^{7}$ Many of the reported "problems" were the result of unexpected chemical reactions or poor quality assurance/quality control during processing.

\section{Limitations to Use:}

The resultant waste volume increase is probably the most serious impediment to stabilizing WSS in cementitious grout. Moisture content rather than chemical reaction with the waste determines the amount of volume increase, in grouting. Using WSS, it should be possible to prepare grout without makeup water. Grout is optimally $25 \%-60 \%$ water; the WSS is between $62 \%$ and $75 \%$ water, by weight. ${ }^{8}$ A $50 \%$ volume increase could result from grouting WSS. However, volumetric increase may be minimized with use of a patented process that mechanically presses a mixture of waste and reactive ASTM Class C fly ash into a solid waste form; the technology has been demonstrated to immobilize/consolidate ash material with no net volume increase.' Water expressed from the waste/fly ash mixture during processing will likely require reprocessing through the PWTP facility.

Grout formulation can be complex for a successfully stabilized waste form, adding to development time and cost. In general, more complex wastes require more complex grout formulations to stabilize all components of the waste and allow proper hardening of the grout. The grout matrix is very sensitive to physical and chemical characteristics of the waste streams; thus, the waste must be thoroughly characterized and the grout components selected with care and in the appropriate proportions. Mattus and Gilliam report that alkali carbonates at moderate concentrations can accelerate initial gel set (i.e., can cause "flash set"), although at very high concentrations set may be retarded due to formation of a dense protective layer around cement clinker grains. ${ }^{10}$ 
TABLE I-Solidified product guidance.

\begin{tabular}{lll}
\hline \multicolumn{1}{c}{ Tests } & \multicolumn{1}{c}{ Methods } & \multicolumn{1}{c}{ Criteria } \\
\hline Compressive strength & ASTM C 39 or D 1074 & $414 \mathrm{kPa}(60$ psi) \\
Radiation stability & See 1983 TP & $414 \mathrm{kPa}$ compressive strength after $10 \mathrm{E}+8^{\circ}$ rads \\
Biodegradation & ASTM G 21 and G 22 & No growth and compressive strength $>414 \mathrm{kPa}$ \\
Leachability & ANS 16.1 & Leach index of $\geq 6$ \\
Immersion & See 1983 TPa & $414 \mathrm{kPa}$ compressive strength after 90 days \\
Thermal cycling & ASTM B 553 & $414 \mathrm{kPa}$ compressive strength after 30 cycles \\
Free liquid & ANS 55.1 & $0.5 \%$ \\
Full-scale & See 1983 TPa & Homogeneous and correlates to lab size test results
\end{tabular}

a The 1983 Branch Technical Position (TP) paper calls for a minimum compressive strength of 345 $\mathrm{kPa}$ ( $50 \mathrm{psi})$. This has been raised to $414 \mathrm{kPa}(60 \mathrm{psi})$ to accommodate an increased maximum burial depth at Hanford of $55 \mathrm{ft}$ (from $45 \mathrm{ft}$ ) as defined by the U.S. Nuclear Regulatory Commission publication, Draft Regulatory Guide on Low-Level Waste Form Stability (a proposed revision to 10 CFR 61, "RG LLW Form Stability," Rev. 4, October 1986).

${ }^{b}$ The 1983 Branch TP calls for a multistep procedure for biodegradation testing: if observed culture growth rated "greater than 1" is observed following a repeated ASTM G 21 test, or any growth is observed following a repeated ASTM G 22 test, longer term testing (for at least six months) is called for, using the Bartha-Pramer Method. From this test, a total weight loss extrapolated for full-size waste forms to 300 years should produce less than a $10 \%$ loss of total carbon in the sample. 


\section{Radionuclide Retention:}

According to Cowgill, leach resistance is: cement<polymers<bitumen< $<$ glass ${ }^{11}$ but, depending on the formulation and the wastes, most radionuclides can be chemically bound very successfully in cement grout. Cesium-137, however, is not successfully retained, due to its high solubility and tendency to migrate outward with the pore water in concrete. Some unpublished work by Kasten et al shows good retention of uranium and 8 of 9 heavy metals during a modified MCC-1 28-day leach test, but poor retention of barium or cesium, from the cement matrix. ${ }^{12}$

Abotsi, in his review of the literature, shows that the stabilization of cesium in cement is subject to a large number of variables. ${ }^{13}$ Among these are temperature, leaching medium, curing time, and additives. Among the latter, those reported effective in reducing Cs-137 leaching are conasauga shale, pottery clay, or grundite; ${ }^{14}$ also montmorillonite, silica fume, or zeolite. ${ }^{15}$

Availability:

Much information exists regarding stabilization of LLW in grout, and on-site expertise exists for formulation, testing, and full-scale application. The waste form technology is commercially available. For treatment of the K-25 raw pond sludge, three of the seven private sector proposals for treatment of this material offered cement-base stabilization as the treatment choice. Permafix, Envirocare, and BNFL proposed to treat the K-25 raw pond sludge using cement grouting as the treatment method. In-drum grouting, large, high-strength monoliths, and containerized granular grout were offered as

options. Since cement-based solidification is currently the most frequently used technology for treating waste materials and is most certain to be offered if treatment/stabilization of this sludge is competitively bid to the private sector, limited bench-scale grouting studies and testing should be performed using surrogate material.

\section{BITUMEN:}

Bitumen (asphalt), a thermoplastic organic polymer, was first used more than 20 years ago to immobilize low-level radioactive wastes. Bitumen solidifies many of the same wastes as the grouting process does. It is insensitive to chemical components of the waste and requires no detailed waste characterization; is reported to have a compressive strength of $130 \mathrm{psi}^{16}$ and can achieve waste volume reduction. Unfortunately, there appears to be little long-term durability data, and there are some significant concerns.

\section{Limitations to Use:}

Waste streams which may cause problems in bitumenization are organic liquids, some nitrates and other oxidizing agents, none of which are constituents of the PWTP WSS. There is a slight flammability risk during processing, but processing temperatures, AT 200 TO $230^{\circ} \mathrm{C}$, are well below the flash point. The process distillate creates a secondary waste stream, which must be treated or disposed of. Bituminization also has relatively high utility requirements. However, the most serious contraindication to bitumen as a waste immobilization agent is its solubility $(0.5 \%)$, which may lead to swelling and degradation, causing, over the long term, increased leaching from the waste form. ${ }^{17}$ On a positive note, Buckley, et al, report that swelling and leaching from bituminous waste forms is greatly reduced when the form is in a well designed repository which gives an unsaturated reducing environment, surely the environment of an above-ground concrete vault. ${ }^{16}$ 


\section{Radionuclide Retention:}

The release rates of Cs-137 from bitumen are reported by Cowgill to be more than two orders of magnitude lower than from cement, slightly lower for Sr-90 from bitumen than from cement, and slightly higher for cobalt from bitumen than from cement. On the other hand, Kasten, et al report cesium leach indexes (LI) of 9.4 from bitumen and 9.0 from cement, not a particularly wide spread. ${ }^{12}$ Buckley and Speranzini evaluated ion-exhange resins immobilized in bitumen, glasses, plastics, and cements over a 60-day period, and found releases of Cs-137 and Co-60 to be lowest for resins in bitumen, followed by glasses, plastics, and cements, in that order. ${ }^{18}$

Although in the short term Cowgill and Buckley both report that radionuclide retention ability of bitumen is much better than cement, long term swelling and degradation is the more important issue. Leaching is increased if bitumen swelling is not kept under control. Other parameters affecting bitumen swelling, in addition to its high water solubility, are inclusion of wastes containing small particle size and strong salt solution, both of which may increase swelling. ${ }^{19}$ It is interesting to note that the solubility constant for bitumen surrounded by water saturated backfill (as opposed to water only) ranged from $10^{-16}$ to $10^{-18} ; 2-3$ orders of magnitude less than in water. ${ }^{20}$ Again, an above ground concrete vault is likely to provide this optimum atmosphere. Additionally, leaching from bitumen decreases with increasing $\mathrm{pH}^{21}$ a parameter likely enhanced by concrete surroundings. Additives such as polypropylene can reduce leaching from bitumen and increase waste loading capability.'

\section{Availability:}

In recent years, bitumenization appears to have fallen out of favor in the US, possibly due to the waste form's perceived long-term stability and durability problems. Although two commercial sources for bitumen waste forms were identified in the mid- to late-80's, ${ }^{12}$. neither is at this time in operation and a search of the business literature revealed no other commercial sources. A discussion with several people involved in waste stabilization and immobilization at ORNL and IT ended with the conjecture that waste form bitumenization is probably not now commercially available in the US (although it may possibly be still available in Europe). ${ }^{22}$

Even if the lack of commercial availability of the bitumen waste form technology and the possible long-term instability of the stored waste forms could be overcome, bitumen is classified as a human carcinogen at Energy Systems. The health hazard rating given it on the MMES MSDS is a 4, which is likely to raise operating and storage/disposal costs to untenable levels due to the resultant required monitoring, surveillance, and personnel protection.

\section{POLYMERIC ENCAPSULATION}

Encapsulation of $L L W$ in polymer materials inciudes use, since the mid-1980's, of epoxy resins, vinyl ester styrene (VES), or polyethylene to create solid wasteforms. Polymers generally have an advantage over cement in that they have a higher solidification efficiency, an assured solidity, and higher waste loading capacities. Data concerning long-term performance is limited; however, the polymeric wasteforms do have relatively high compressive strengths, and they permit up to $70 \%$ waste loading (up to $90 \%$ and more for resin beads). ${ }^{11,23}$ Volume reduction is probable (wasteforms $1 / 3$ the volume of cement are typical). They can incorporate most wastes. Particle size and density, though, have a limited range to be compatible with molten polyethylene; the particles could otherwise float or sink during cooling. ${ }^{24}$ Like bitumen, these polymeric materials are relatively insensitive to the chemical components, so that the waste should not need detailed characterization. Except for epoxy 
resins, the polymer processes demand dewatered wastes; thus, a secondary waste stream is generated. The feed to a thermal drying operation should be $<30 \%$ water by volume. ${ }^{25}$ Since WSS is upwards of $75 \%$ water, a combination of mechanical (filter press, centrifuge, etc.) and thermal drying may be required to ready the material for polumeric encapsulation. Most of the polymeric processes are lowheat technologies. The polymeric processes need to be closely controlled. They are relatively complex, due to the probable number of ingredients (solidification agents, catalysts, etc.) and the addition of a dewatering process. Some polymers, VES for example, are slightly flammable during processing. If complete inflammability is desired, Diversified Technologies Services, Inc. (Diversified Technologies) offers an alternative to the VES technology that is non-flammable and performs very well, although it is not yet approved by the NRC. ${ }^{26}$ Another polymerization technology uses sulfur polymer cement, developed to use the sulfur by-product from the petroleum industry. This is a promising but evolving technique. There is no long-term durability data available, and research and development is needed. More information on this and other evolving technologies for sludge treatment and/or stabilization is available in the Technology Logic Diagram. prepared for the pond waste management alternatives study. ${ }^{27}$

\section{Availability:}

VES is commercially available. It was developed by the DOW Chemical Company and is supplied locally by Diversified Technologies. According to this vendor, the VES waste form is in compliance with 10CFR Part 61 , is approved by the NRC for stabilization of classes $A, B$, and $C$ radioactive wastes, and meets Hanford WAC for burial. ${ }^{26}$ VES forms containing ion-exchange resins performed well in wetting/drying tests by Morgan and Bostick. ${ }^{23}$ Polyethylene encapsulation is a more recent innovation, still under development. ${ }^{28}$ It, too, is available from Diversified Technologies.

Polyethylene has produced wasteforms with a compressive strength of 1960 psi at $50 \%$ waste loading, and performs nearly as well at $70 \%$ loading. In this process, dry, granular waste is mixed with polyethylene granules and slowly forced through an extruder system with heating $\left(130-160^{\circ} \mathrm{C}\right)$ and pressure, where it converts to the molten form. ${ }^{29}$ An interesting possibility, according to Paul Kalb of Brookhaven National Laboratory, is use of landfill polyethylene, thereby reducing landfill consumption. ${ }^{28}$

\section{Leachability:}

Kalb states that gamma radiation up to $10^{8} \mathrm{rad} / \mathrm{hr}$ can actually strengthen and improve the polyethylene wasteform. Cowgill reports LI's of 8 to 12 , in "polyester or epoxy resin" with no specific radionuclides defined; he states Cs release rate from VES is similar to that from bitumen and at least 2 orders of magnitude better than that from cement. ${ }^{11}$ Diversified Technologies subjected the polymerized VES end product to multiple TCLP tests and found it to be "non-toxic and nonhazardous". ${ }^{26}$

\section{Costs:}

Overall cradle-to-grave costs may well be compatible with or lower than grouting. Operating costs are a complicated issue, with uncertainties arising in commodities, transportation, and disposal costs. The price of feed material is high compared with cement or bitumen, although it fluctuates with oil market factors. Despite the high feed cost, though, Rocky Flats claimed a large project cost savings by using polyethylene rather than grouting. ${ }^{13}$ The waste loading capacity of the polymers is superior to that of cement, and overall storage/disposal costs are lower because of the lower wasteform volume. Utilities costs for the process would be lower than for bitumenization or vitrification, and waste characterization costs would be lower than for grouting. For polyethylene, Kalb estimates approximate capital costs at $\$ 1 \mathrm{M}$ for an integrated system or $\$ 250 \mathrm{~K}$ for extruder hardware only. ${ }^{29}$ On the other 
hand, if a vendor supplies and operates a mobile treatment unit, as proposed by Diversified Technologies for VES, the capital cost would be borne by the vendor.

\section{MICROWAVE SINTERING/VITRIFICATION}

Vitrification or glass encapsulation is recognized by the U.S. EPA as "Best Available Demonstrated Technology" for the treatment of many types of hazardous and/or radioactive waste ${ }^{30}$; their 'Handbook' provides an excellent summary of the technology. Depending on the glass formers present in (or added to) the waste, the treated product may be a brick-like ceramic, a stone-like monolith, or an amorphous glass. The resultant refractory waste forms are typically stable, dense, high-strength, leachresistant solids with no free liquids. Glass forming elements and fluxing agents include $\mathrm{Si}, \mathrm{Al}, \mathrm{Fe}, \mathrm{P}$, $\mathrm{B}$, and alkalai/alkaline earth metals; suitable concentrations of these constituents may be present in the waste, or may be added as a reagent. Silicon is typically added in the form of diatomaceous earth (often from filter aids, already present to some extent in many sludges), but it can be added in the form of contaminated soil/sediment, asbestos, ash, or other material used for co-disposal; this is referred to as "minimal additive waste stabilization" (MAWS), which is currently being demonstrated for the Fernald Site. ${ }^{31}$

\section{Volume Reduction:}

Solidification of wastewater treatment sludges or their surrogates by vitrification has been demonstrated using conventional joule-heating and microwave sintering technologies. ${ }^{32,33} \mathrm{Del} \mathrm{Cul}$, et al, report sludge volume reductions of 5 to 10 , or more, depending on moisture content. Researchers at Savannah River demonstrated an $86 \%$ volume reduction for a dewatered nickel plating sludge and spent filter aid vitrified at $1150^{\circ} \mathrm{C}^{34}$ In crucible studies performed at Clemson University using surrogate WETF sludge, waste loadings of $50-70 \%(w / w)$ sludge dry solids in glass waste forms have been achieved, representing net volume reductions of up to $85 \%$, relative to the original wet sludge (at $\sim 70 \%$ water content). In addition to dehydration and decomposition loss of carbonate or nitrate ions, the melting process represents a significant densification, further reducing waste form volume.

\section{Radionuclide Retention:}

Vitrified waste forms typically demonstrate excellent retention of radionuclides, but during the melting process (at temperatures in the range of $800-1400^{\circ} \mathrm{C}$ ) relatively volatile radionuclides (e.g., radiocesium) may partition in part to the off-gas, requiring HEPA filtration. The temperature at which an element attains a total vapor pressure (for all chemical species in equilibrium) of $10^{-6}$ atmospheres is referred to as the "volatility temperature"; for $\mathrm{Cs}$, the volatility temperature is about $375^{\circ} \mathrm{C}$ (no $\mathrm{Cl} / \mathrm{Cl}_{2}$ present) to $500^{\circ} \mathrm{C}\left(\mathrm{Cl} / \mathrm{Cl}_{2}\right.$ present), whereas the corresponding values for $\mathrm{Sr}$ are $1250^{\circ} \mathrm{C}$ (no $\mathrm{Cl} / \mathrm{Cl}_{2}$ present) to $925^{\circ} \mathrm{C}\left(\mathrm{Cl} / \mathrm{Cl}_{2}\right.$ present $) .^{35}$ Ritter et al report a typical material balance for $\mathrm{Cs}$ fed to a high-temperature melter of about $64 \%$ in the glass and about $1 \%$ in the off-gas collection tank; $\mathrm{Sr}$ was quantitatively retained in the glass melt. ${ }^{36}$ However, it is claimed that use of a cold-cap melter (solidified glass/waste at $\sim 200^{\circ} \mathrm{C}$ above a molten zone at $\sim 1150^{\circ} \mathrm{C}$ ), in conjuction with low air flow, can retain $>>90 \%$ of the $\mathrm{Cs}$ in the melter. ${ }^{37}$

Availability:

Several vendors, including Stir-Melter, EnVitCo, and GTS Duratek can provide joule melter technology. At present, no off-site vendor vitrification services are available, although such service is anticipated by mid-1996, in a co-operative effort between Duratec and ChemNuclear at Barnwell, $\mathrm{SC}^{34}$ Dr. Terry White (ORNL Fusion Energy Division) can design and have fabricated suitable sized 
microwave melter technology, and EET Corp. offers commercial capability. Other related technologies include the Vortec Corp. Cyclone Melter, and plasma torch systems (Retech, Inc., Plasma Technology Corporation, Mason Hanger, etc.), and Molten Metal Technology. Descriptions of some of these are in the Logic Diagram prepared for the pond waste management alternatives study. ${ }^{27}$

In Co-operative Research and Development Agreements, with partnerships between DOE/EM-50, Savannah River Laboratories, Clemson University, SEG/Oak Ridge, and Energy Systems Waste Management Organization, a transportable melter system is being procured for initial operation in Oak Ridge to demonstrate the vitrification option for the Y-12 West End Treatment Facility (WETF) sludge. Like the WSS, the WETF sludge contains about $70 \%(\mathrm{w} / \mathrm{w})$ water, with the solids being predominantly calcium carbonate; thus the glass formation chemistry should be essentially identical. Information gained in use of this vitrification system, including process economics, should be transferable to prospective processing of the WSS. Similar information, with use of surrogate material, can currently be acquired by the vitrification research facility at Clemson University (also described as the DOE/Industrial Waste Vitrification Center) or the Catholic University of America Vitreous State Laboratory, and Battelle Pacific Northwest Laboratory.

\section{CONCLUSIONS}

Of the technologies discussed here, those we consider most deserving of consideration for possible treatment/immobilization of ORNL WSS are cement grouting, polymeric encapsulation, and sintering/vitrification.

Cement has been used for several decades to immobilize LLW. There are some difficulties in deploying it with WSS. Cement will increase in volume with waste incorporation, and it will require meticulous formulation and development for optimum retention of Cs-137. However, although the expected volume increase after grouting is undesirable, grouting must still be considered a viable option until a better technology is identified by this treatability study and is offered for full-scale treatment.

Polyethylene, VES, ceramic, or glass, on the other hand, make durable, dense wasteforms, containing no water. Polymeric encapsulation will probably allow retention of $\mathrm{Cs}-137$ within the wasteform because operating temperatures are well below the volatility threshold for cesium. Vitrification and perhaps also microwave sintering may drive off appreciable cesium into a secondary waste stream which will require treatment (e.g., recycle through the PWTP facility). With removal of cesium, the wasteforms may be acceptable to Envirocare.

Thus, in order to meet customer specifications of smallest possible wasteform volume, radionuclide stabilization (or removal), and minimum free liquid, we believe polymeric encapsulation or vitrification/microwave sintering are likely to be the best of the more innovative alternatives presented here. However, grouting is an established technology that cannot be ruled out. 
For this project, we suggest the following steps:

1). Determine the elemental composition and structure of a sample of the actual WSS. A sample has been obtained from storage inventory and is in the process of being analyzed.

2). Prepare an initial surrogate WSS, based on the recipe supplied by Tim Kent. ${ }^{38}$ Compare elemental composition and structure with actual WSS. Modify surrogate as needed, to conform with WSS composition and structure. The purpose is to accurately assess the properties of wasteforms prepared with WSS without the necessity of rad protection measures during testing.

3). Prepare grout forms incorporating surrogate WSS. Measure volume increase, compressive strength, leaching behavior of surrogate radionuclides, and amount of free liquid. This will provide a comparative basis for evaluating the recommended stabilizations by polymeric encapsulation or microwave sintering. It is expected that all of the above specifications will be more acceptably met by the latter technologies than by grouting.

4). Contract with Diversified Technologies to perform bench-scale tests with VES and our prepared surrogate. This type of polymeric encapsulation lends itself well to bench-scale work. A proposal from Diversified Technologies is attached, which specifies that they will do process control testing and the TCLP on the resultant wasteforms. In addition, compressive strength, volume change, and amount of free liquid will be determined. These performance parameters should be adequate to assess the applicability of this technology. If they are qualified as a potential vendor, Diversified Technologies has the ability to move on site with portable process equipment, set up the process, decontaminate it, and demobilize.

5). Using the prepared WSS surrogate, perform microwave sintering, testing, and limited crucible melt studies. Determine volume change, compressive strength, and leaching behavior of radionuclides from the form. Testing should include borosilicate glass, calcium silicate, ceramic, and phosphate stabilization and melt densification.

We believe this will provide the necessary guidance for selection of treatment technology, in the near term, for your objective of reducing the volume of WSS stored on site. 


\section{REFERENCES}

1. T. L. Sams, R. C. Jones, J. T. Grumski, Evaluation of Available Mixed Waste Disposal Sites, ES/ER/TM-45, 1993.

2. T. L. Sams, R. C. Jones, R. J. Sams, Evaluation of Potential Disposal Sites for Environmental Restoration Waste Streams, ES/ER/TM-109, March 1994.

3. A. J. Mattus, MMES, memo to G. R. Cunningham, November 6, 1994.

4. E. M. Franz, M. Furhmann, B. Bowerman, S. Bates, R. Peters, Proposed Waste Form Performance Criteria and Testing Methods for Low-Level Mixed Waste, BNL-52436 (DOE/MWIP-30), August 1994.

5. J. H. Westsik, Jr., Characterization of Cement and Bitumen Waste Forms Containing Simulated Low-Level Waste Incinerator Ash, NUREG/CR-3798, 1984.

6. J. L. Shoemaker, MMES, memo to D. E. Beck, November 22, 1994.

7. T. F. Lomenick (ed.), Proceedings of the Workshop on Radioactive, Hazardous, and/or Mixed Waste Sludge Management, Report CONF-901264, Martin Marietta Energy Systems, Inc., 1992.

8. S. Joost, MMES, letter to M. T. Morris, March 26, 1987, and

T. E. Kent, MMES, letter to G. Cunningham, October 13, 1994, respectively.

9. R. D. Spence, D. R. Trotter, C. L. Francis, I. L. Morgan, "Stabilization/Solidification of TSCA Incinerator Ash", in Proceedings of the 1994 International Incineration Conference, University of California, Irvine, 1994, pp. 633-638.

10. C. H. Mattus, T. M. Gilliam, A Literature Review of Mixed Waste Components: Sensitivities and Effects upon Solidification/Stabilization in Cement-Based Matrices, ORNL/TM-12656, March 1994.

11. M. G. Cowgill, A Comparison of Solidification Media for the Stabilization of Low-Level Radioactive Wastes, BNL 52304, October 1991.

12. J. L. Kasten, H. W. Godbee, T. M. Gilliam, WIT: ACase Study in Waste Immobilization Technology, MMES, 1989 (unpublished).

13. G. M. K. Abotsi, D. A. Bostick, W. D. Bostick, Evaluation of Interim and Final Waste Forms for the Newly-Generated Liquid Low-Level Waste Flowsheet, MMES, to be published.

14. E. W. McDaniel,O. K. Tallent, T. L. Sams, D. B. Delzer, W. D. Bostick, "Bases for Selecting Cement-Based Waste Forms for Immobilizing Radioactive Wastes", Scientific Basis for Nuclear Waste Management, XII, eds. W. Lutz and R. C. Ewing, Materials Research Society, 1989, pp. 421-30.

15. A. Kumar, D. M. Roy, "Retardation of $\mathrm{Cs}^{+}$and $\mathrm{Cl}^{-}$Diffusion using Blended Cement Admixtures", J. Am. Ceram. Soc., 69(4), 356-60. 
16. L. P. Buckley, N. B. Tosello, B. L. Woods, "Leaching Low-Level Radioactive Waste in Simulated Disposal Conditions", ASTM Spec. Tech. Publ., 1033(Environ. Aspects Stab. Solidif. Hazard. Radioact. Wastes), 1989, pp. 330-42.

17. H. Matsuzuru, S. Fojiri, N. Moriyama, Improvement of the Asphalt-Waste Products in Leachability. Leachability of the Asphalt Products Containing BWR Evaporator Concentrate, Report JAERI-M-8864, Japan At. Energy Res. Inst., Tokai Res. Establ., Tokyo, Japan, 1980.

18. L. P. Buckley, R. A. Speranzini, "Evaluation of Matrices for Immobilizing Ion-Exhange Resins", from Proceedings of the LAEA Co-coordinated Research Meeting on the Treatment of Spent IonExchange Resins, Otaniemi, Finland, June 2, 1980.

19. K. Broderson, B. Mose Pederson, A. Vinther, Comparative Study of Test Methods for Bituminized and Other Low- and Medium-Level Solidified Waste Materials, RISO-M-2415, Risoe National Lab., Roskilde, Denmark, 1983.

20. L. P. Buckley, "Waste Packages and Engineered Barriers for the Chalk River Nuclear Laboratories' Disposal Program (Shallow land burial.)", Report \# AECL--8853; CONF-8506114--3; DE86900292, from International Seminar on Radioactive Waste Products Suitability for Final Disposal, Julich, F. R. Germany, 10 June 1985.

21. S. H. Lee, K. S. Chun, E. K. Lim, "Studies on the Bituminization Process of Radioactive Liquid Waste", Journal of the Korean Nuclear Society, 7(3) 1975, pp. 213-22.

22. R. Spence, MMES, personal communication to D. E. Beck, 11/18/94.

E. Stine, IT Corporation, personal communication to D. E. Beck, 11/18/94.

23. I. L. Morgan, W. D. Bostick, "Performance Testing of Grout-Based Waste Forms for the Solidification of Anion Exchange Resins", Hazardous Wastes, Standard Technical Publication 1123, ASTM, Philadelphia, PA, 1992.

24. J. W. Snider, "Polyethylene", WSTA-108-OPW, in Technology Logic Diagram. Pond Waste Management Alternatives Study: Technology Evaluation Data Sheets, ed. R. L. Fellows, MMES K-25 Site, October 1993.

25. U.S. EPA, Technological Approaches to the Cleanup of Radiologically Contaminated Superfund Sites, EPA/540/2-88/002, United States Environmental Protection Agency Office of Research and Development, Washington D.C., August 1988.

26. C. E. Jensen, President, Diversified Technologies Services, Inc., Knoxville, SludgeHammer ${ }^{T M}$ Processing System for ORNL WSS Project, personal communication to W. D. Bostick, MMES, Nov. $18,1994$.

27. R. L. Fellows et al, Technology Logic Diagram, Pond Waste Management Alternatives Study: Technology Evaluation Data Sheets, MMES, K-25 Site, October 1993.

28. P. D. Kalb, et al, as cited in G. M. K Abotsi, D. A. Bostick, W. D. Bostick, Evaluation of Interim and Final Waste Forms for the 
Newly-Generated Liquid Low-Level Waste Flowsheet, August 1994, to be published.

29. "Radionuclide and Metals Captured, Stabilized in Polyethylene Coat", Environmental Remediation Technology, June 29, 1994, pp. 127-28.

30. U.S. Environmental Protection Agency, Vitrification Technologies for Treatment of Hazardous and Radioactive Waste, EPA/625/R-92/002, May 1992.

31. I. L. Pegg, "MAWS: A Program for the Development and Demonstration of an Integrated, Multiple Technology, Multiple Wastestream Treatment System for the Fernald Site", in A. A. Moghissi et al. (eds.) Mixed Waste (Proc. 2nd International Symp., 1993).

32. D. M. Bennert, T. J. Overcamp, D. Bickford, "Wastewater Treatment Sludge Vitrification: Summary of Savannah River Site M-Area Surrogate Demonstrations" in Proceedings of the 1994 International Incineration Conference, University of California, Irvine, 1994, pp. 335-341.

33. G. D. Del Cul, W. D. Bostick, R. E. Adamski, W. A. Slover, P. E. Osborne, R. L. Fellows, T. L. White, "Solidification of Waste Sludges using Microwave Heating", in Proceedings of the 1994 International Incineration Conference, University of California, Irvine, 1994, pp. 615-620.

34. C. M. Jantzen, J. B. Pickett, W. G. Ramsey, "Reactive Additive Stabilization Process for Vitrification of Hazardous and Mixed Waste", CONF-930873--19 (DE94012383), Proceedings of the Second International Mixed Waste Symposium, A. A. Moghissi, et al (eds.), 1994.

35. J. A. D. Stockdale, W. D. Bostick, D. P. Hoffmann, H.-T. Lee, Surrogate Formulations for Thermal Treatment of Low-Level Mixed Waste, Part 1: Radiological Surrogates, DOE/MWIP-15, January 1994.

36. J. A. Ritter, N. D. Hutson, J. R. Zamecnik, J. T. Carter, "Immobilization of Simulated High-Level Radioactive Waste in Borosilicate Glass: Pilot Scale Demonstrations", in G. G. Wicks, D. F. Bickford, L. R. Brunnell (eds.), Ceramic Transactions, Vol. 23, 1991, pp. 295-307.

37. M. J. Plodinec, Westinghouse Savannah River Co., personal communication to W. D. Bostick, 1 Dec. 1994; C. A. Cicero, D. F. Bickford, D. M. Bennert, T. J. Overcamp, West End Treatment Facility Simulated Sludge Vitrification Demonstration, WSRC-RP-1111, August 1993.

38. T. E. Kent, MMES, memo to G. R. Cunningham, 10/13/94. 